\title{
Methodology for Determination of the Number of Equipment Malfunctions Due to Voltage Sags
}

\author{
Alena Otcenasova ${ }^{1, *}$, Roman Bodnar ${ }^{2}$, Michal Regula $^{1}$, Marek Hoger $^{1}$ and Michal Repak ${ }^{1}$ \\ 1 Faculty of Electrical Engineering, Department of Power Electrical Systems, University of Zilina, \\ Univerzitna 1, 01026 Zilina, Slovakia; Michal.Regula@fel.uniza.sk (M.R.); \\ Marek.Hoger@fel.uniza.sk (M.H.); Michal.Repak@fel.uniza.sk (M.P.) \\ 2 The Electricity Distribution Company, Pri Rajcianke 2927/8, 01047 Zilina, Slovakia; roman.bodnar@sse-d.sk \\ * Correspondence: Alena.Otcenasova@fel.uniza.sk; Tel.: +421-41-513-2162
}

Academic Editor: Rodolfo Araneo

Received: 15 February 2017; Accepted: 15 March 2017; Published: 20 March 2017

\begin{abstract}
This article deals with the assessment of the reliability of sensitive equipment due to voltage sags. The most frequent problems of power quality are voltage sags. Equipment that cannot withstand short-term voltage sag is defined as sensitive device. Sensitivity of such equipment can be described by the voltage-tolerance curves. A device (generator) to generate voltage sags (also interruptions) with duration at least $1 \mathrm{~ms}$ has been designed and developed for this purpose. Equipment sensitive to voltage sags was tested using this generator. Overall, five types of sensitive equipment were tested: personal computers, fluorescent lamps, drives with speed control, programmable logic controllers, and contactors. The measured sensitivity curves of these devices have been used to determine the number of trips (failures) due to voltage sags. Two probabilistic methods (general probability method and cumulative probability method) to determine probability of equipment failure occurrence are used. These methods were applied to real node in the distribution system with its actual performance of voltage sags/swells. The calculations also contain different levels of sensitivity of the sensitive equipment.
\end{abstract}

Keywords: power quality; voltage sag; sensitivity of equipment; probability of equipment trip

\section{Introduction}

New technologies are increasingly dependent on electrical energy with defined level of voltage quality. Especially, industrial processes are fully automated and require continuous supply of electrical energy. These automated processes utilize equipment that is sensitive to the voltage quality, mainly voltage sag. The most common equipment sensitive to the voltage sags includes: personal computers (PC), fluorescent lamps (FL), programmable logic controllers (PLC), adjustable speed drives (ASD), contactors, converters, microprocessors, and so on. It is very important to keep industrial processes at the utmost level of functionality. Any downtime can be directly correlated with the loss of the production, profits, and income. Moreover, distribution companies are facing an increasing number of customer complaints [1,2]. Out of different types of power quality disturbances (e.g., interruptions, transients, voltage unbalance, flicker, current and voltage harmonics, and voltage swells and sags), voltage sags are the most frequent and can cause malfunction of equipment. Therefore, the ability of the industrial process equipment to withstand voltage sags is becoming more crucial than in the past. In addition, sensitive equipment is usually connected to the back-up power supply so that it does not trip during the disturbance. The invasion of electronic devices, controls and other types of digital devices is the heart of the problem [3,4].

The faults in the power systems are the major cause of voltage sags in the electric delivery system. Three-phase (symmetrical) faults lead to severe sags at many buses over the wide geographical 
region (depending on the network topology). These faults, fortunately, are very rare in the power system. Single line-to-ground fault and other asymmetrical faults typically cause sags with higher magnitudes, however they are much more common in the power system. Adverse weather conditions (lighting strikes), contamination of insulators, and animal contact are other typical causes of faults in the power system [5-8].

The voltage sag is defined as a sudden reduction of supply root mean square (RMS) voltage in interval from $90 \%$ to $5 \%$ of the rated voltage at the voltage frequency and with its duration from 10 $\mathrm{ms}$ to $1 \mathrm{~min}$. Some authors use the term "dip" instead of "sag" for this phenomenon. Voltage sags are generally originated by starting of large motor loads or network faults as a rapid change of network impedance. In addition, reacceleration of large motor loads or connection of transformers (loads) can modify the shape of the voltage sag or can fairly influence characteristic of voltage sag. Voltage sag can cause the trip of the sensitivity equipment in a process and/or can disrupt the entire process. It is dependent on interconnection of individual sensitive equipment in the work process. Equipment sensitivity to the voltage sag depends substantially on the applications, control settings and specific load type [9]. Thus, it is very often difficult to determine which characteristics of given voltage sags are most likely to cause equipment trips, or the case when equipment will ride-through the event. The most frequently used characteristics are the magnitude and duration of the voltage sag. Other, less commonly used, characteristics are also phase-angle shift (known as phase jump), point-on-wave in time of sag initiation, unbalance and missing voltage [10-14].

Any method for determining the number of device trips is based on a comparison of power quality (PQ) characteristics offered by the utility and load/process sensitivity of the customers [1]. The aim of each method is to determine as accurate as possible the total number of device trips for a certain period. Many authors use different calculation methods. Park et al. [15] uses the new concept of the "area of severity" and the impact rankings of network lines and buses are also addressed. Area of severity and the annual expected sag frequency (i.e., the expected number of voltage sags exceeds the voltage threshold) are determined for three different sensitive load buses. The author uses stochastic assessment of voltage sags. Chan and Milanovic [16] uses failure risk assessment. This author does not use equipment status (trip or no trip) determined by voltage sags. Instead, the response of the equipment is represented by the risk of equipment failure, with values ranging from 0 to 100 . Failure risk of 0 means that the equipment is unlikely to fail, while failure risk of 100 means that the equipment will certainly fail. Failure risk values from 1 to 99 represent the uncertainty of equipment response. This is made possible using a fuzzy logic based model. This method use Duration Severity Index and Magnitude Severity Index as the concept of voltage sag severity indices. Some authors also consider other impacts that may affect the accuracy of results: fault frequency of fault type (for voltage sag performance calculating), number of fault positions on lines, fault resistance, time-varying fault rates, and time-varying loading of the network $[17,18]$.

\section{Sensitive Equipment}

In order to establish the consequences of voltage sags at a given point of common coupling (PCC), the characteristic of voltage sag is compared with voltage-tolerance curve of sensitive equipment for finding its performance. That means whether the equipment will trip (malfunction) or ride-through the sag with specified characteristics. For simplification, many studies assume that sensitive equipment has rectangular characteristic (i.e., voltage magnitude during the voltage sag has constant value). Thus, one of the most common methods for determination of the equipment sensitivity to the voltage sags is used: a duration-magnitude plot, as shown in Figure 1. Nevertheless, some equipment, such as household electronic appliances and motor-contactors, has non-rectangular voltage-tolerance characteristics in practice. The detailed information of equipment and its immunity to the voltage sags can be obtained either from available standards, from equipment manufacturer or from overall laboratory tests of equipment. However, there is a variety of equipment types, with characteristics 
that may change during the operation (depend on the protection setting, mode of operation, and other factors) $[19,20]$.

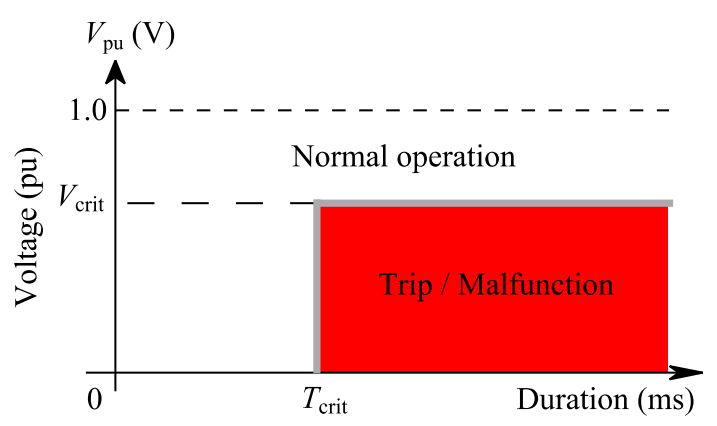

Figure 1. Voltage-tolerance characteristic.

Typical rectangular voltage-tolerance characteristic of sensitive equipment is shown in Figure 1. If specific values of voltage sag are situated in red area, the equipment will trip, and otherwise it will not trip.

\subsection{Inclusion an Uncertainty of Sensitive Equipment}

Many publications (e.g., [21-31]) focused on laboratory tests describing sensitivity characteristics of different sensitive equipment depend on equipment type, loading of equipment and power system conditions. All of them consider that sensitive equipment have more or less rectangular characteristics. By measuring several sensitive equipment units of the same type, characteristics inserted to the voltage magnitude-duration chart are obtained. For generalization of all sensitive equipment behavior (of a given type, e.g., personal computer), area of uncertainty using characteristics of measured equipment is created. Therefore, the area of uncertainty for voltage-tolerance characteristics of sensitive equipment can be described as a shaded area in the voltage sag magnitude-duration chart shown in Figure 2a. The area of uncertainty is limited by four threshold values. The voltage sag duration is determined by two values $\left(T_{\min }\right.$ and $T_{\max }$ ) and magnitude of voltage sag is determined by minimal and maximal voltage magnitudes $\left(V_{\min }\right.$ and $\left.V_{\max }\right)$. As shown in Figure 2, voltage sags with duration longer than specified duration threshold $T_{\max }$ and deeper than specified magnitude threshold $V_{\min }$ will cause trip or malfunction of the equipment. In other cases, if magnitude of voltage sag is above specified magnitude threshold $V_{\max }$ and duration is shorter than $T_{\min }$, equipment will withstand the voltage sag. It is impossible to determine behavior of equipment during the voltage sag with the specific magnitude and duration with $100 \%$ accuracy, if the value of voltage is situated in area of uncertainty (shaded area).

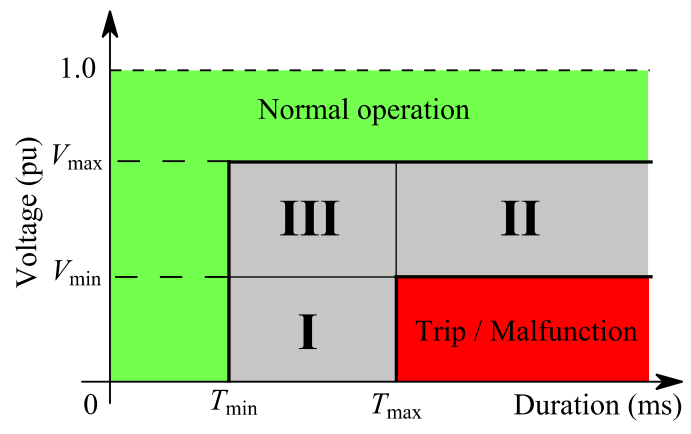

(a)

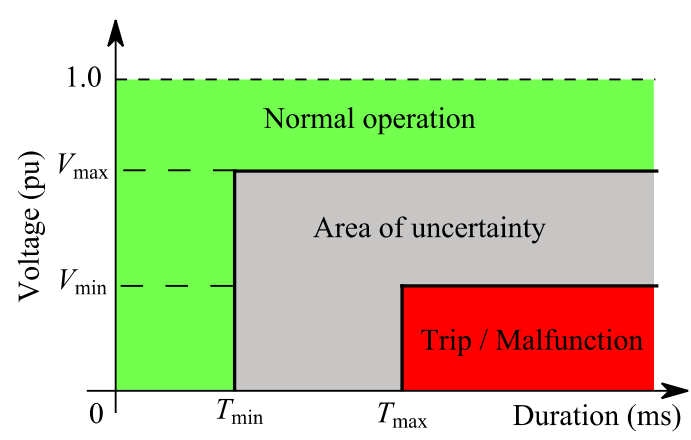

(b)

Figure 2. Area of uncertainty: (a) defined by voltage-tolerance characteristics; and (b) divided into sub-regions. 
This study is focused on five types of sensitive equipment, namely PC, FL, ASD, PLC and contactors. It is assumed that these types of equipment have rectangular characteristics and may occur anywhere in shaded area of individual type. Break point on characteristic is called knee point of characteristic (curve) and is always situated in sub-region III (Figure 2a). Threshold values (Table 1) are adopted on the basis of the laboratory tests and published results of sensitivity equipment.

Table 1. Threshold values of the sensitive equipment.

\begin{tabular}{ccccc}
\hline \multirow{2}{*}{ Equipment Type } & \multicolumn{2}{c}{ Voltage Range } & \multicolumn{2}{c}{ Duration Range } \\
\cline { 2 - 5 } & $\boldsymbol{V}_{\boldsymbol{\operatorname { m i n }}} \mathbf{( p u )}$ & $\boldsymbol{V}_{\max }(\mathbf{p u})$ & $\boldsymbol{T}_{\min }(\mathbf{m s})$ & $\boldsymbol{T}_{\max }(\mathbf{m s})$ \\
\hline PC & 0.48 & 0.63 & 50 & 110 \\
FL & 0.22 & 0.62 & 10 & 55 \\
PLC $^{1}$ & 0.46 & 0.76 & 30 & 380 \\
ASD $^{2}$ & 0.71 & 0.89 & 5 & 20 \\
\hline
\end{tabular}

\footnotetext{
${ }^{1}$ Electric Power Research Institute (EPRI) carried out a comprehensive tests of the six PLC commonly used in industrial processes. The task was to determine the ability of PLC to withstand voltage sags with different depth and duration. All six PLC were programmed with the same "power-quality-test" algorithm. To carry out an overall measurement of the PLC, it is necessary to consider several aspects: correctness of (CPU) operation, and correctness of discrete and analog outputs. Furthermore, consideration should be given to the behavior of the equipment due to voltage sags: shutdown and automatic restart of PLC, shutdown and manual restart of PLC, faulty control signals. Due to difficulty of PLC measuring and testing, results were taken from the research institute study [32]. ${ }^{2}$ Due to complexity of measuring voltage-tolerance curves, results were taken from comprehensive study results [22]. The author of the publication considers all kinds of voltage sags as well as changes of devices' mechanical characteristics at given voltage sags.
}

For definition of threshold values of sensitive equipment, programmable power source from Applied Precision Company was used. The power source is controlled using LabView program and CompactRIO-9074 from National Instruments Company (Austin, TX, USA). The program generates voltage sag defined by user with specific value of remaining voltage and duration of voltage sag. Using certificated power network analyzer (ENA330, Elcom, Brno, Czech Republic), definite values (remaining voltage and duration) defined by user in program were verified.

\subsubsection{Voltage-Tolerance Curves Measurement for Personal Computers}

Seven PCs were tested for measurement of voltage sags resistance of devices (voltage-tolerance curves measurement). Tests of the devices were performed for the various phase instants of voltage, with values ranging from $0^{\circ}$ to $90^{\circ}$ with an increment of $18^{\circ}$. Individual measured curves were regularly arranged in graphical dependence. Extreme characteristics were curves obtained for phase instants values $90^{\circ}$ and $0^{\circ}$. This is why we considered only phase instants of these angles for further testing. When setting the angle of voltage sag to $0^{\circ}$, voltage sag starts at voltage crossing the value 0 towards positive half-wave. When setting the angle of voltage sag to $90^{\circ}$, voltage sag occurs at the moment of maximum voltage value in positive half-wave. Description of individual PC characteristics is given in Table 2. Compared parameters are source, $\mathrm{CPU}$, hard disk drive (HDD), random access memory (RAM) and graphic processing unit (GPU).

Table 2. List and description of tested PCs.

\begin{tabular}{lccccc}
\hline No. & Source & CPU & HDD & RAM & GPU \\
\hline PC1 & LC-B300ATX 300 W & AMD Athlon 166 MHz & $82.3 \mathrm{~GB}$ & $256 \mathrm{MB}$ & ASUS V9520 \\
PC2 & EuroCase ATX-400 W & Intel Celeron 2.8 GHz & $76.7 \mathrm{~GB}$ & $512 \mathrm{MB}$ & NVIDIA GeForce 7300 GS \\
PC3 & EuroCase ATX-400 W & Intel Celeron 2.8 GHz & $76.7 \mathrm{~GB}$ & $512 \mathrm{MB}$ & NVIDIA GeForce 7050 \\
PC4 & CWT PUFP-4055 450 W & Intel Core 2 Quad 2.66 GHz & $500 \mathrm{~GB}$ & $2+2 \mathrm{~GB}$ & ASUS EAH5770 \\
PC5 & HP-D3006A0 300 W ATX & Intel Celeron 2.6 GHz & $320 \mathrm{~GB}$ & $2+2 \mathrm{~GB}$ & Intel Express \\
PC6 & FSP Group 250 W & AMD Phenom 2.2 GHz & $320 \mathrm{~GB}$ & $1+1 \mathrm{~GB}$ & ATI Radeon \\
PC7 & LiteOn PS-5301 300 W & AMD Phenom 2.2 GHz & $500 \mathrm{~GB}$ & $1+1 \mathrm{~GB}$ & ATI Radeon \\
\hline
\end{tabular}


Figure 3 shows voltage-tolerance curves for all seven tested PCs with phase instants of voltage sags $0^{\circ}$ and $90^{\circ}$ and curves for information technology CBEMA (Computer and Business Equipment Manufacturers' Association) and ITIC (Information Technology Industry Council). The fact that voltage-tolerance curves of all tested PCs are situated under the curve ITIC means they comply with resistance defined by ITIC curve. We take into consideration only voltage sags, not overvoltage. However, the original curve CBEMA, which also defines the area of voltage events resistance of devices, were not met by three PCs, namely: PC2, PC6 and PC7. By comparing the tolerance curves of PCs for the phase instant of voltage $0^{\circ}$ and $90^{\circ}$, the difference is approximately $10 \mathrm{~ms}$. Measured tolerance curves at phase instant of voltage $90^{\circ}$ and $0^{\circ}$ have critical voltage values $U_{\text {krit}}$, which are in the interval from 0.48 to $0.63 \mathrm{pu}$ and critical values of duration $T_{\text {krit }}$ are in interval from 50 to $110 \mathrm{~ms}$.
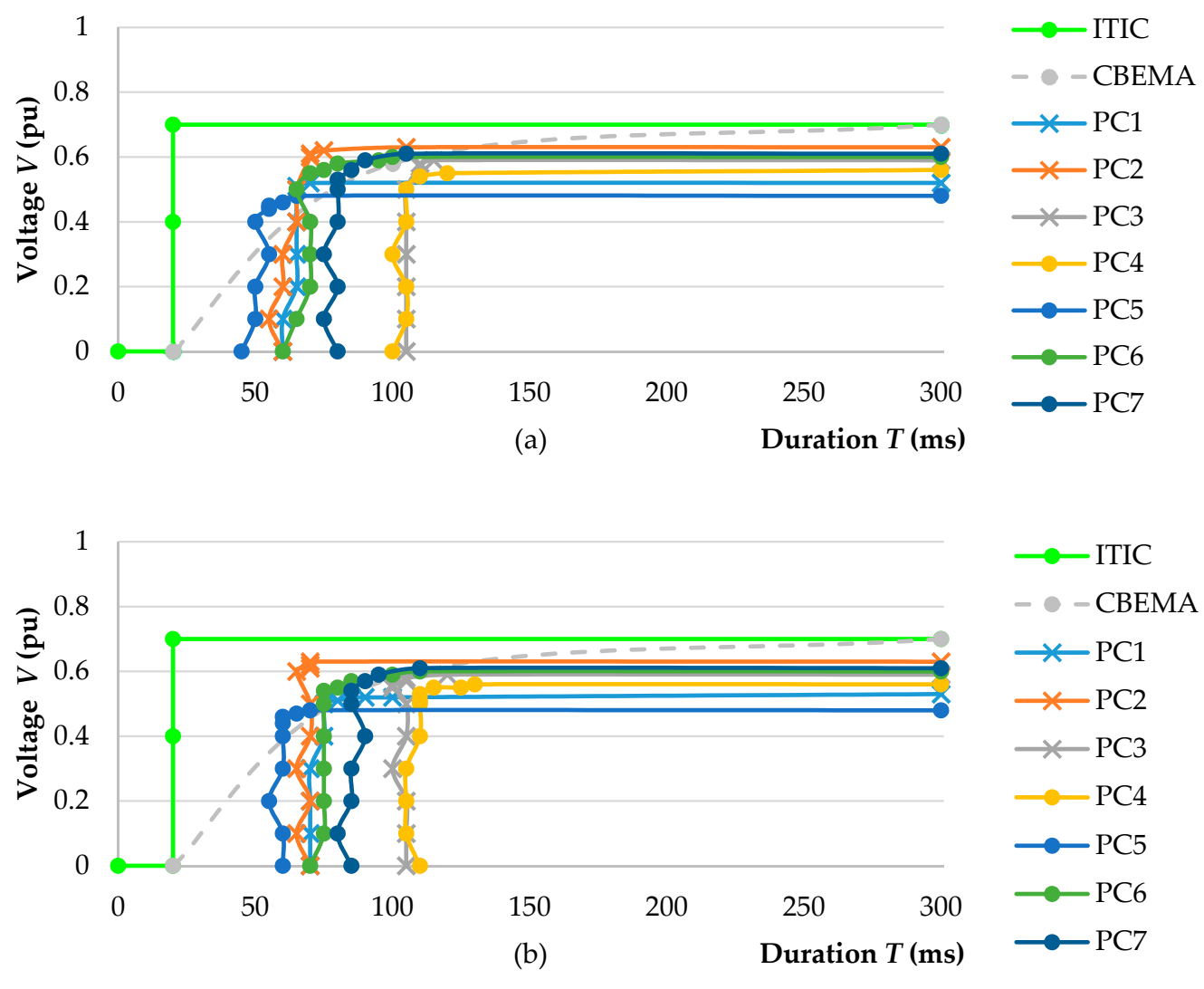

Figure 3. Voltage-tolerance characteristic of personal computers: (a) at phase instant of voltage $0^{\circ}$ and (b) at phase instant of voltage $90^{\circ}$.

\subsubsection{Measurement of Voltage-Tolerance Curves for Fluorescent Lamps}

Five fluorescent lamps (Table 3) were tested for measurement of voltage sags resistance of fluorescent lamps (voltage-tolerance curves). Testing of devices was performed the same way as in Section 2.1.1.

Table 3. List of tested fluorescent lamps.

\begin{tabular}{cccl}
\hline No. & Ballast & Power & Type \\
\hline FL1 & electromagnetic & $36 \mathrm{~W}$ & tube \\
FL2 & electronic & $11 \mathrm{~W}$ & CFL \\
FL3 & electronic & $8 \mathrm{~W}$ & CFL \\
FL4 & electronic & $8 \mathrm{~W}$ & CFL \\
FL5 & electromagnetic & $18 \mathrm{~W}$ & tube \\
\hline
\end{tabular}


Figure 4 shows voltage-tolerance curves at phase instant of voltage sag occurrence $0^{\circ}$ (Figure $4 \mathrm{a}$ ) and at phase instant of voltage sag occurrence $90^{\circ}$ (Figure $4 \mathrm{~b}$ ). Critical voltage values and tolerance curves duration are almost unchanged. All curves, except the first fluorescent lamp FL1, showed nearly rectangular tolerance curve. It is considered that all curves have rectangular character for simplification. The critical voltage values are from 0.22 to $0.62 \mathrm{pu}$ and the critical values of duration are from 5 to $55 \mathrm{~ms}$.

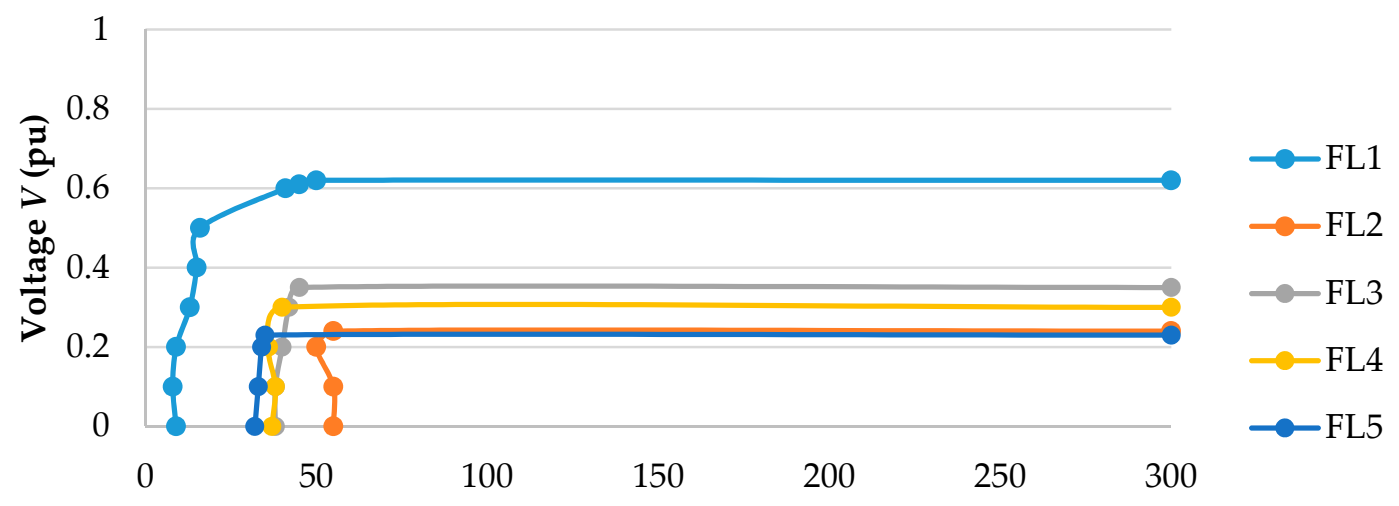

(a)

Duration $T(\mathrm{~ms})$

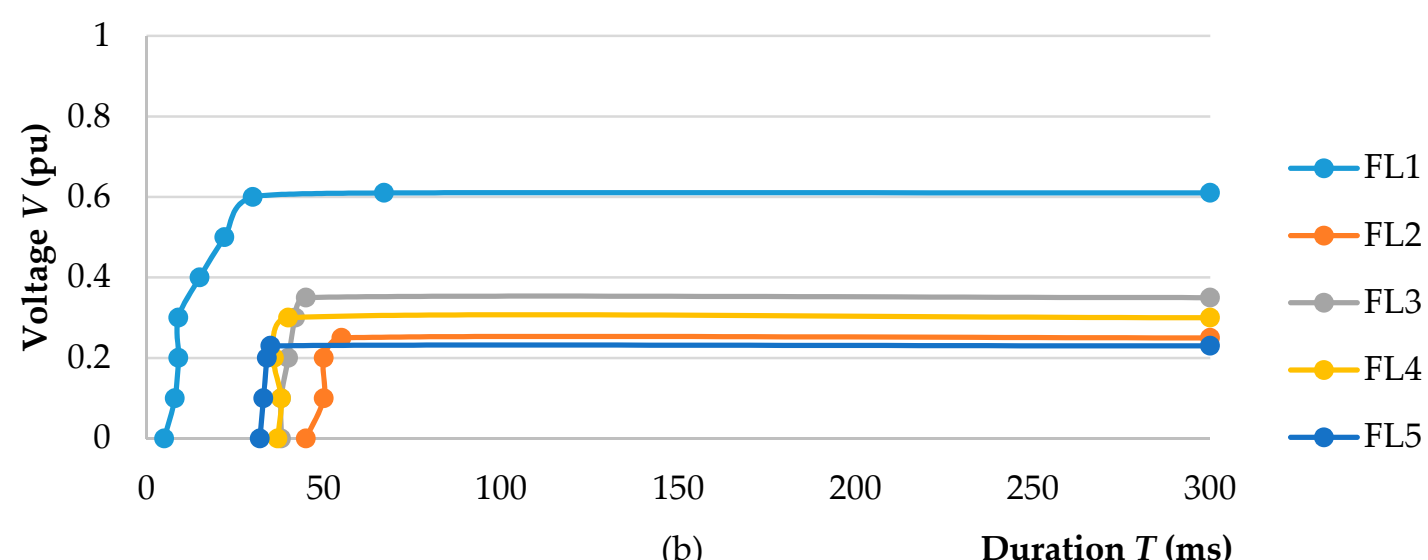

Figure 4. Voltage-tolerance characteristic of fluorescent lamps: (a) at phase instant of voltage $0^{\circ}$ and (b) at phase instant of voltage $90^{\circ}$.

\subsubsection{Measurement of Voltage-Tolerance Curves for Contactors}

Figure 5 shows voltage-tolerance curves for three-phase contactors. Measurement was carried out for five different contactors with parameters listed in Table 4 .

Table 4. List of tested contactors.

\begin{tabular}{cccc}
\hline No. & Type & Nominal Currant $\boldsymbol{I}_{\mathbf{N}}(\mathbf{A})$ & Isolated Voltage $V_{\mathbf{I}}(\mathbf{V})$ \\
\hline C1 & AC3 $/ 10$ V25M & 21 & 500 \\
C2 & AC3/10 V25M & 21 & 500 \\
C3 & K25E & 21 & 660 \\
C4 & Schneider LC1D25 & 25 & 680 \\
C5 & ABB A40 & 60 & 1000 \\
\hline
\end{tabular}

Tolerance curves measurement at phase instant $0^{\circ}$ showed that curves are not rectangular. As we can see in Figure 5a, contactors are more resistant to deep voltage sags. This phenomenon is caused by 
the energy stored in magnetic field of the contactor coil. When the voltage on the contactor's solenoid changes suddenly, the inductance of the solenoid induces a transient DC current. This DC current helps to keep the main contacts closed. This effect is strongest when the fault starts in the instant, when the magnetic flux is close to maximum (at phase instant of voltage close to $0^{\circ}$ ). If the fault starts in the phase instant when the voltage is close to $90^{\circ}$, the magnetic flux is minimal, thus there is no energy in the magnetic field to induce a transient DC current helping to keep the contacts closed and the characteristic is close to rectangular (Figure 5b). Figure 5a shows curves summary at phase instant of voltage $0^{\circ}$. At this phase instant, the most resistant was contactor $\mathrm{C} 5$, where, at power supply interruption, it withstood until the voltage sag duration exceeded $110 \mathrm{~ms}$. Measured tolerance curves at phase instant of voltage $90^{\circ}$ have nearly rectangular character and have similar waveforms as the previous tested devices. Critical voltage value in this case (phase instant of voltage $90^{\circ}$ ) is from 10 to $18 \mathrm{~ms}$. Curves summary at phase instant of voltage $0^{\circ}$ is shown in Figure 5b. To simplify the calculations in the area of uncertainty for contactors, it is necessary to make some modifications of this area. Figure 6a shows theoretical area of uncertainty for contactors. Red curve represents measured tolerance curve for phase instant $0^{\circ}$. It would be difficult to determine probability distribution for this curve and therefore is modified (dotted curve). With this approximation, the modified area of uncertainty is divided into smaller sub-regions in Figure 6b. In this case, there are more sub-regions than at other mentioned sensitive equipment. This modification significantly simplifies the calculation of probability of equipment trip for the area of uncertainty. Probability distribution in the four sub-regions has two different tendencies of sensitivity. The first one assumes a combination of uniform and/or exponential probability distribution (Figure 6c) and the second one is a combination of uniform and/or normal probability distribution (Figure 6d) [33].

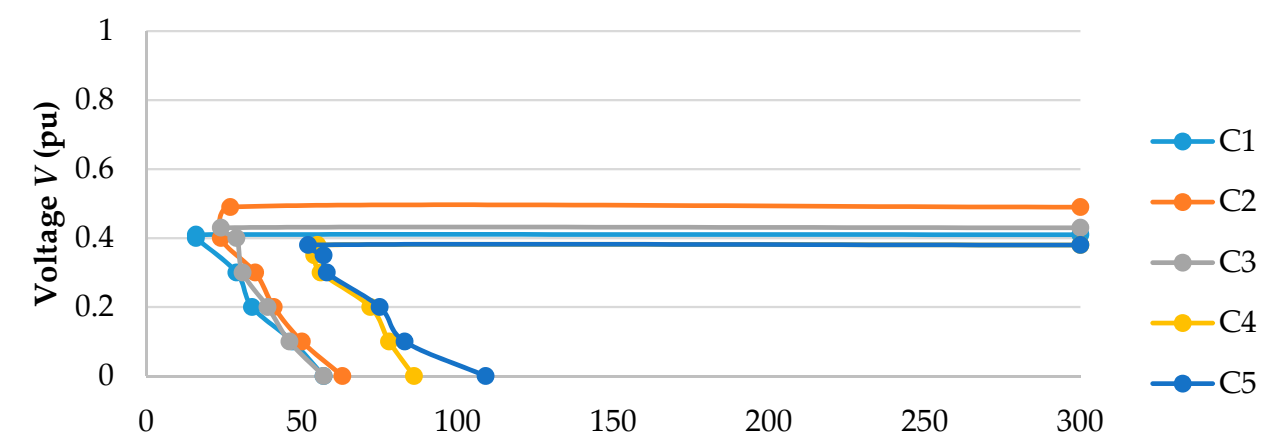

(a) Duration $T$ (ms)

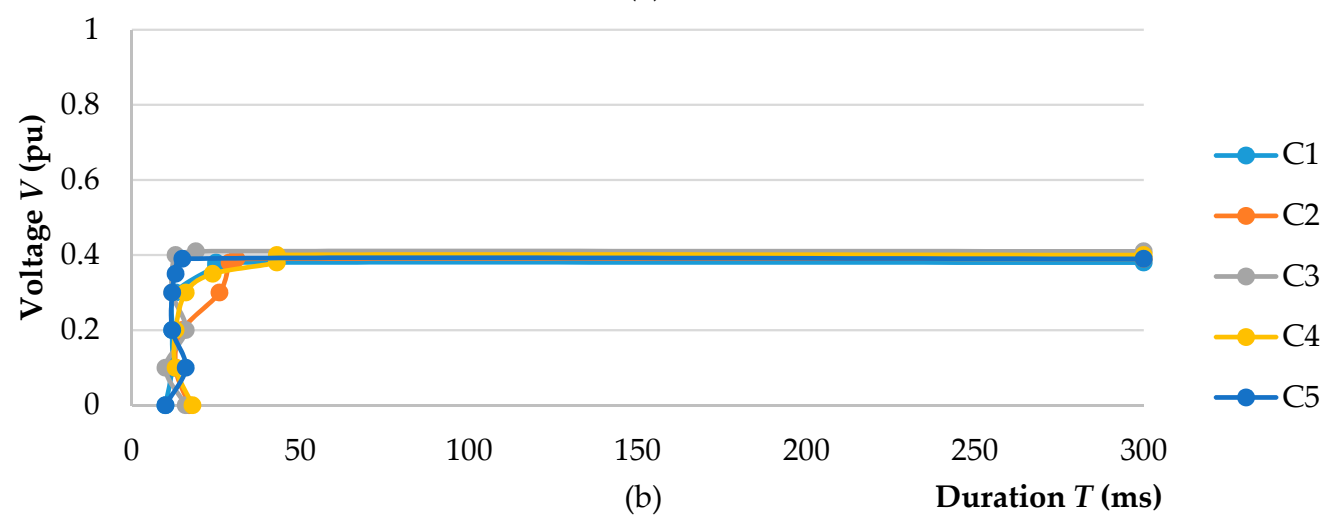

Figure 5. Voltage-tolerance characteristic of contactors: (a) at phase instant of voltage $0^{\circ}$; and (b) at phase instant of voltage $90^{\circ}$. 


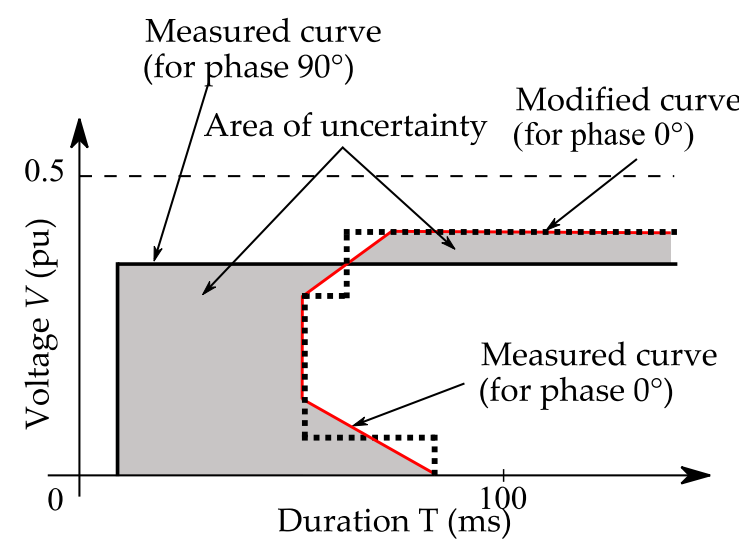

(a)

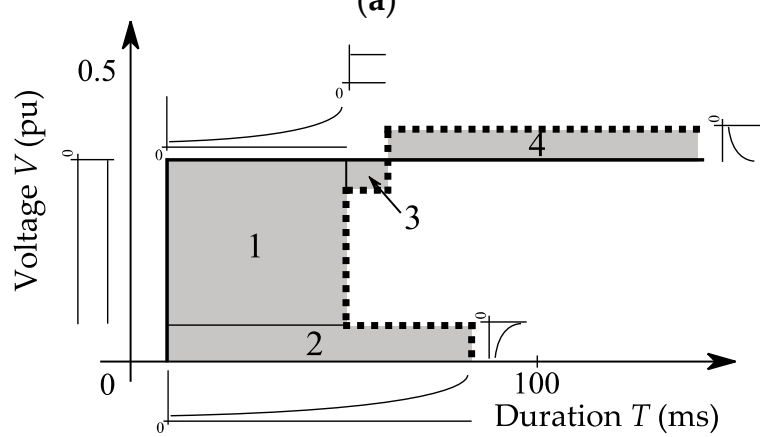

(c)

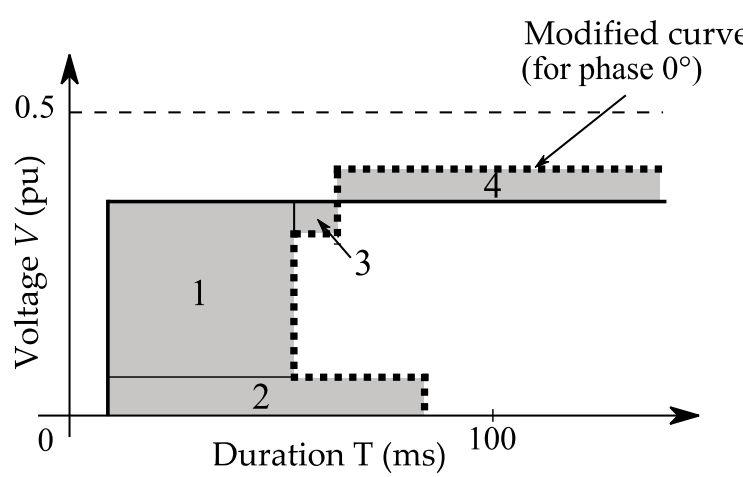

(b)

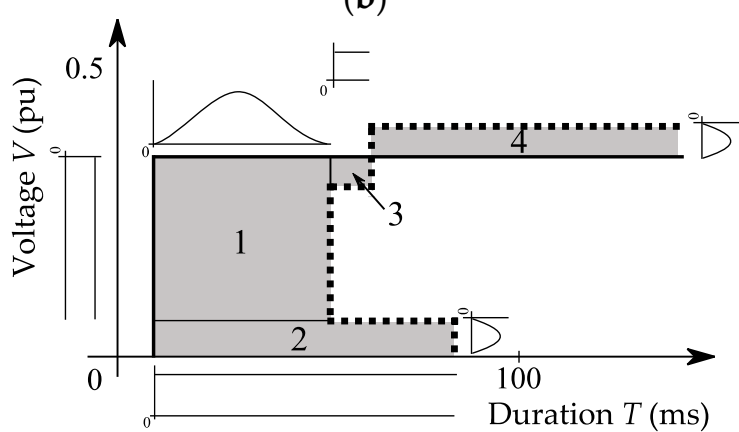

(d)

Figure 6. Area of uncertainty for contactors: (a) theoretical area of uncertainty for contactors; (b) area of uncertainty distribution; (c) considering the combination of uniform and/or exponential distribution in the individual sub-regions; and (d) considering the combination of uniform and/or normal distribution in the individual sub-regions.

The area of uncertainty is formed in Figure 7 from measured curves of tested contactors (shaded area) and modified tolerance curve for phase instant of voltage $0^{\circ}$ (red dotted line). According to the procedure described above, the final area of uncertainty for contactors, which consists of four sub-regions, is specified.
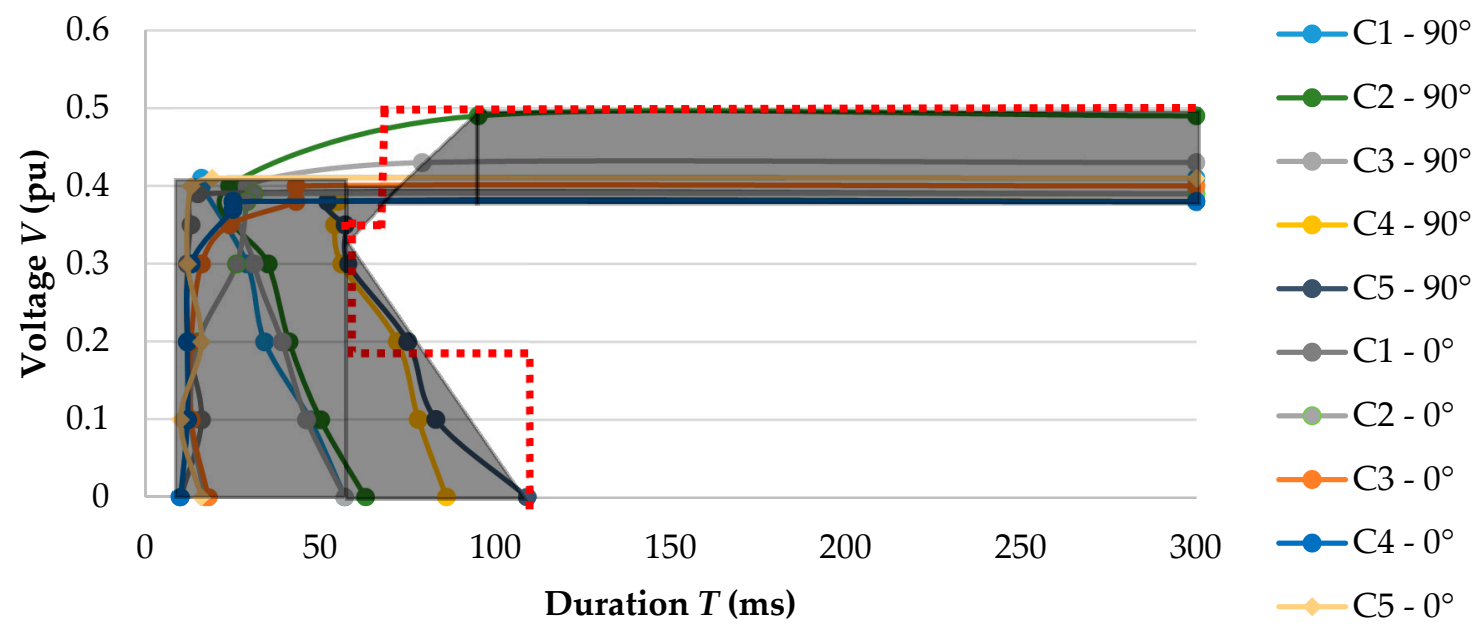

Figure 7. Area of uncertainty for contactors (shaded area), curve modification for phase instant $0^{\circ}$ (red dotted line). 
The final area of uncertainty for contactors is defined by four sub-regions by plotting the thresholds (Figure 8). These thresholds are the input values used in the following calculations and simulations.

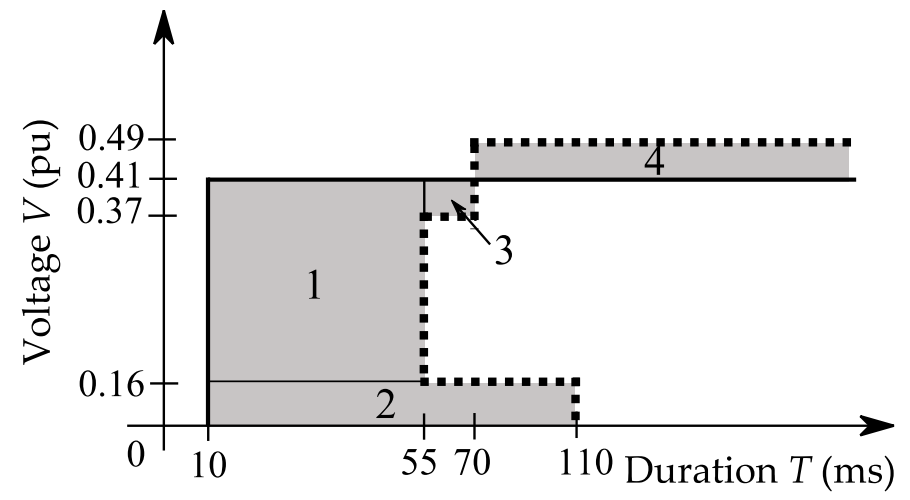

Figure 8. Individual sub-region thresholds for contactors.

\subsection{Test Stand for Voltage Sags Generation}

For the purpose of voltage sag sensitivity testing, authors developed and tested stand build up from a customized programmable voltage source and a certified power quality analyzer. The structure of the test stand is shown in Figure 9.

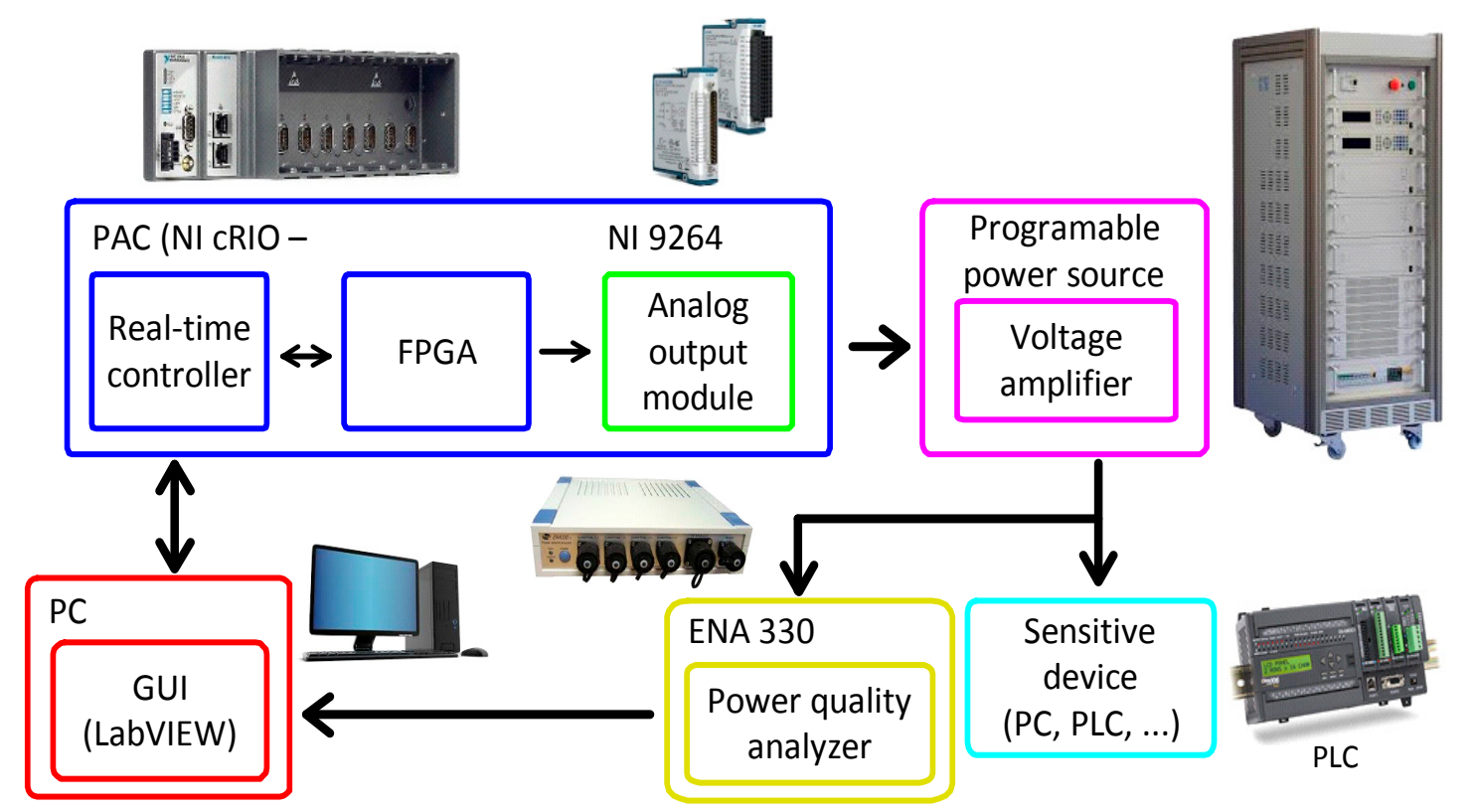

Figure 9. Structure of the voltage sag sensitivity test stand.

Tested devices (PCs, PLCs, relays, etc.) are powered from an Applied Precision 8325B programmable power source. This type of power source is originally used for calibration of electricity meters and the built-in signal generator cannot change the output voltage with dynamics required for voltage sag sensitivity testing. Therefore, it was necessary to replace the built-in signal generator with a custom signal generator.

The custom signal generator was built using a NI cRIO 9074 PAC (National Instruments Hungary Kft, Debrecen, Hungary, Programmable Automation Controller). This embedded controller contains a $400 \mathrm{MHz}$ real-time processor and a Xilinx Spartan 2M gate field programmable gate array (FPGA) 
with eight-slot chassis for input/output modules. For this application, a NI 9264 analog output module was used.

The PAC is capable to generate an output signal with amplitude $\pm 10 \mathrm{~V}$ with sampling frequency of $20 \mathrm{kHz}$. The real time processor generates for each phase a sinusoidal signal with unit amplitude sampled at 400 samples per period. Signal generated for each phase is then split in to a collection of five-sample-wide data windows. These data windows are then multiplied with the user defined voltage amplitude multiplier and then sent to FPGA using a DMA FIFO (Direct Memory Access First In-First Out) buffer at the rate of $4 \mathrm{kHz}$. FPGA then uses its precise timing to write the samples to the analog output module. When all samples of actual data are successfully written to the analog output module, FPGA sends an interrupt request signaling to the real-time processor that a new data window should be written to the FIFO buffer. As the real-time processor is not only responsible for the signal generation, but also handles the communication with the remote graphical user interface (GUI) application, there is possibility of some short duration lagging of the main signal generation loop. This could lead to interruption of generated signal. Therefore, there are normally at least three data windows buffered for the FPGA array, so even during some short time freezing of the main real time processor the generation continues smoothly without interruption.

The voltage sag (or voltage interruption) is achieved by changing the amplitude multiplier to a defined level for a defined time interval. As all five samples in a data window are multiplied by the same value, the shortest possible interval of voltage sag is $250 \mu \mathrm{s}$. It is easy to reprogram the voltage sag control timer loop to enable also shorter voltage changes-from the software point of view, the limit is the sample rate of the analog output module. However, in this test stand configuration, it is not possible to use such a high fault dynamics because very fast voltage changes often trigger the internal protections of the power amplifier, so the dynamic of the voltage changes was in fact limited by the programmable power source.

As the reaction of sensitive devices to voltage sag is often strongly dependent on the phase instant of the voltage sag occurrence, the software also enables defining the desired point of wave (POW) for the start of the fault [34]. Because of the generator architecture defined above, the point-of-wave feature has the angle resolution of $4.5^{\circ}$ at the $250 \mu$ s period of the fault timer loop. However, this angle resolution is sufficient for most purposes. Basic properties of the signal generator and the power source are summarized in Table 5.

Table 5. Basic properties of the signal generator and the power source.

\begin{tabular}{cccc}
\hline \multicolumn{2}{c}{ Signal Generator } & \multicolumn{2}{c}{ Power Source } \\
\hline Sample rate & $20 \mathrm{kHz}$ & Number of phases & 3 \\
Signal frequency & $50 \mathrm{~Hz}$ & Base frequency & $40-70 \mathrm{~Hz}$ \\
Signal amplitude & $\pm 10 \mathrm{~V}$ & Output voltage & $0-600 \mathrm{~V}$ \\
Fault timer resolution & $250 \mu \mathrm{s}$ & Power & $2000 \mathrm{VA}$ \\
POW resolution & $4.5^{\circ}$ & & \\
\hline
\end{tabular}

\subsection{Interconnection between Sensitive Equipment}

For determination of the number of equipment malfunctions due to voltage sags, knowledge about mutual connection of sensitive equipment that participate on the certain process is required. In this regard, the response of entire process to the voltage sag is strongly dependent on the response of particular equipment participating in the certain process [14].

Probability of equipment trips due to voltage sags is calculated in the area of uncertainty of sensitive equipment. The overall probability of the process trips can be calculated by mutual connections of individual sensitive equipment and their probability of particular trips. In general, the overall probability of a process trip is written as: 


$$
P_{\text {trip }}=1-\left[\prod_{i=1}^{m}\left(1-\prod_{j=1}^{n} p_{i, j}\right)\right]
$$

where $p_{i, j}$ is the cumulative probability of tripping of $j$ th equipment unit of the $i$ th serially connected equipment group; $n$ is the number of parallel-connected equipment in the equipment group; and $m$ is the number of series-connected equipment/equipment groups. Typical connections of equipment in usual processes are depicted in Figure 10 [13].

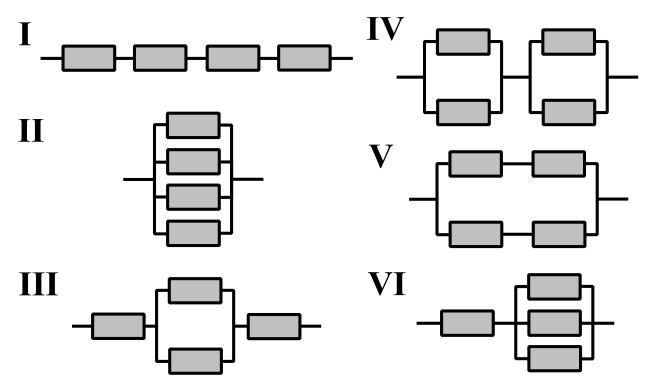

Figure 10. Typical connection of sensitive equipment in process.

\subsection{Different Types of Sensitivity}

Based on the voltage-tolerance curve location within the area of uncertainty for the certain equipment or equipment type, there is a general trend to judge this area according to various types of probability functions. Type of probability functions for two independent random variables $V$ and $T$ is determined according to sensitivity of individual equipment [3]:

- Low sensitivity: Equipment has very good ride-through capabilities against voltage sags; it can be represented using reverse exponential functions.

- High sensitivity: Highly sensitive equipment has very poor ride-through capability against the voltage sags, therefore probabilities are assumed in exponentially decreasing order from high to low voltage magnitude threshold and from low to high duration magnitude threshold.

- Moderate sensitivity: This type of sensitivity using normal probability functions with assuming that the high probability is in the middle of area of uncertainty (i.e., knee of equipment sensitivity), for example in sub-region III (Figure 2a).

- Uniform sensitivity: If it is assumed that any location of equipment voltage-tolerance curve is within the area of uncertainty with equal probability, it can be represented by uniform probability functions for $\mathrm{V}$ and $\mathrm{T}$ within their threshold ranges.

In order to assess the influence of difference fault distributions on voltage sags, these probability distributions can be extended with additional variations at each type of sensitivity. For example, at normal distribution probability, it is possible to consider the same mean value and different standard deviation or different mean value and the same standard deviation [5].

\section{Determination of the Number of Equipment Malfunctions}

The determination of the number of equipment malfunctions in the red area is easy (Figure 2, area where equipment certainly will trip). However, the calculation is problematic in the area of uncertainty (shaded area), where it is necessary to calculate with probability of equipment trips. Distribution of probability with considering different sensitivities can be used with one equipment and with one type of sensitivity (mentioned above) at the time. For this purpose, two probability methods are presented. The first probability method uses cumulative probability approach and second one uses general probability approach. The duration and magnitude of the voltage sags are two statistically independent discrete random variables $[26,35]$. 


\subsection{Cumulative Probability Method}

This approach calculates with occurrence of voltage sag and consequence of voltage sag. According to the characteristic of the voltage sag and type of sensitivity of equipment, whether equipment will ride-through or trip due to voltage sag is decided. The variation in equipment sensitivity can be used by terms of univariate random variable $(V)$ in sub-region II (Figure 2a), univariate random variable $(T)$ in sub-region I (Figure 2a), and also bivariate random variable $(T, V)$ in sub-region III (Figure 2a). $T$ and $V$ are assumed to be independent discrete random variables ( $V$ is the voltage magnitude-threshold changing between $V_{\min }$ and $V_{\max }$ and $T$ is voltage duration-threshold changing between $T_{\min }$ and $T_{\max }$ ). Probability distribution function for bivariate random variable $(T, V)$ is determined by joint probability distribution functions of univariate random variables $F_{X}(T)$ and $F_{Y}(V)(2)$. Total equipment trips for bivariate variable TET $(T, V)$ can be determined as follows [3]:

$$
\begin{gathered}
F_{X Y}(T, V)=F_{X}(T) F_{Y}(V), \\
T E T(T, V)=F_{X Y}(T, V) \cdot N(T, V),
\end{gathered}
$$

where $F_{X Y}(T, V)$ is probability of trip of the particular equipment according to Equation (2) within range intervals of sag magnitude and sag duration. $N(T, V)$ is the number of voltage sags expected at the specified site over specified interval of time.

Finite number of total equipment trips TET for individual sensitive equipment at the specified site over specified period of time is define as follows:

$$
T E T=\sum_{\mathrm{T}} \sum_{\mathrm{V}} T E T(T, V)
$$

\subsection{General Probability Method}

This method uses ordinary (or general) probabilities instead of cumulative probability methods as mentioned in Section 3.1. It is assumed that all the trip contributions are produced by various sensitivity curves of the equipment. Considering one sensitivity curve at one time, trip contributions are summed up and multiplied by specific probability of voltage sag occurence [3].

Ranges of intervals are the same as in the method mentioned above $\left(T_{\min } \leq T \leq T_{\max }\right.$ and $V_{\min }$ $\left.\leq V \leq V_{\max }\right)$. It is possible to determine univariate probability density functions $f_{\mathrm{Y}}(V)$ and $f_{\mathrm{X}}(T)$ for both random variables. Probability density function for bivariate random variable $(T, V)$ can be obtained by joining these probability functions and it is given by Bayes rule [36] as:

$$
f_{X Y}(T, V)=f_{X}(T) f_{Y}(V)
$$

where $f_{X Y}(T, V)$ is the join of probability density function for a voltage-tolerance curves situated within the area of uncertainty. Total sum of probabilities $f_{X Y}(T, V)$ of sub-region III is equal to unit for the knee of the equipment having rectangular voltage-tolerance curves situated inside sub-region III. The expected number of trips (ENT) for particular equipment is calculated using joined probability function (Equation (5)) and number of expected equipment trips. This can be defined as follows:

$$
\begin{gathered}
E N T(T, V)=f_{X Y}(T, V) \cdot N(T, V) \\
E N T=\sum_{\mathrm{T}} \sum_{\mathrm{V}} \operatorname{ENT}(T, V)
\end{gathered}
$$

where $N(T, V)$ is the number of expected equipment trips (with corresponding voltage-tolerance curves). Voltage sag magnitude $V$ and voltage sag duration $T$ have to be within the ranges of intervals ( $T_{\min } \leq T \leq T_{\max }$ and $V_{\min } \leq V \leq V_{\max }$ ). Total expected number of trips of individual sensitive equipment at a given bus (PCC) is obtained using summation (Equation (7)) within whole range of 
intervals of sag magnitudes and durations (defined by threshold values of voltage magnitude and duration of area of uncertainty, Figure 2).

\section{Study Case}

Methodology for probability estimation of equipment malfunctions/trips due to disturbances in power system is performed by reason of estimation of financial losses in the network. Every equipment trip in consequence of disturbance is connected with direct economic losses (caused by malfunctions themselves) and indirect/relative losses. Always, somebody has to bear these financial losses, either at side of customer or at side of distribution system operator. According to proposed methods, it is easy to know where the worst points of network are (points of network where the highest financial losses in consequence of voltage sags are).

The proposed study was used for three types of sensitive equipment: PC, PLC and ASD. The real conditions include more aspects as considered in this study. Some aspects are not considered for purpose of simplifying the determination of trips. For instance, for more accurate determination of the equipment trip, it is needed to specify the actual operating time of the equipment in the process. Next aspect is the connection of the single-phase equipment to different phases (only one third of total number of equipment trip at bus). For comprehensive result, asymmetrical sag will be considered the voltage sag with magnitude of lowest voltage of all phases.

These probability methods were applied to the simple radial network of power system. Measurements in the real Slovak distribution power network were used as input data for obtaining voltage sag/swell performance in specific point (bus) (Figure 11). Measurement point was at first bus of radial network. The duration of measurement was one year.

In the performed study, it is assumed that all three types of sensitive equipment are connected at the specified bus. For all types of equipment, number of trips is determined with considering different type of sensitivity (mentioned above in Section 2.4). Due to verification of the results of expected number of equipment trips, it was calculated with both cumulative method and general method (Section 3).

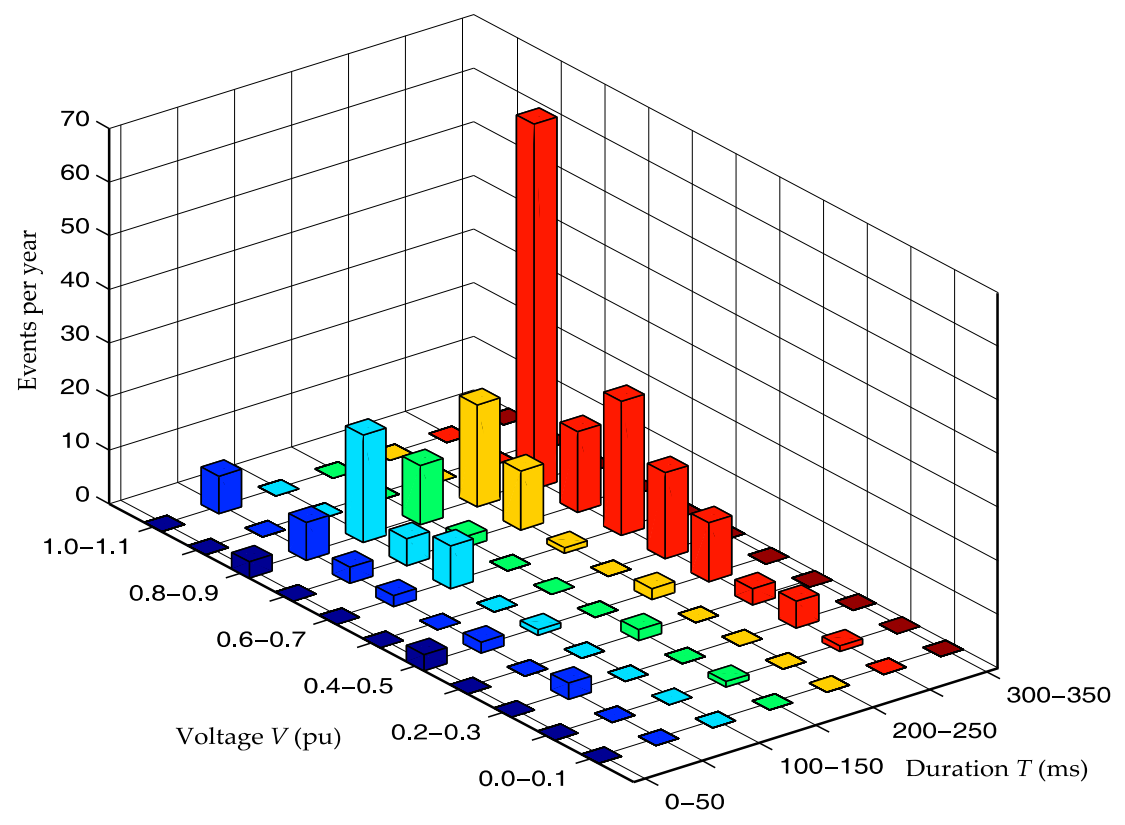

Figure 11. Performance of voltage sags at specified bus of supply system.

The calculated values that represent number of the given sensitive equipment trips are defined for a specific time period. In this case, it is a period of one year, because data of voltage sags frequency 
are also for the time period of one year. For shorter time periods, prediction of equipment trips is more accurate, e.g., with regard to the annual period. As it is a prediction, the result cannot be considered as $100 \%$ value because most voltage sags are unpredictable and random (e.g., voltage sags occurred due to weather conditions or disturbances in the system). In addition, network configuration change affects the spread of voltage sags, and therefore this aspect should not be forgotten. The results have increased informative value if voltage sags frequency data are used from a longer time period.

A program in MATLAB where all input data have been processed was created for calculating data using the probabilistic methods. It was necessary to parameterize used probability functions properly in order to achieve relevant results. The calculation procedure is the same for all considered devices, except the contactors.

\subsection{Number of PC Trips}

Using probabilistic methods mentioned in Section 3, and with consideration of different types of sensitivity (Section 2.4), it is possible to quantify the number of the equipment trips for a specific time period; in this case, the period of one year. The measured critical thresholds for personal computer are $V(0.48-0.63 \mathrm{pu})$ and $T(50-110 \mathrm{~ms})$.

\subsubsection{General Probability Method}

The number of expected equipment trips $N(T, V)$, within specified critical values, corresponding to various voltage-tolerance curves for PCs in the considered node, is shown in Figure 12. At one time point, there is only one voltage-tolerance curve considered.

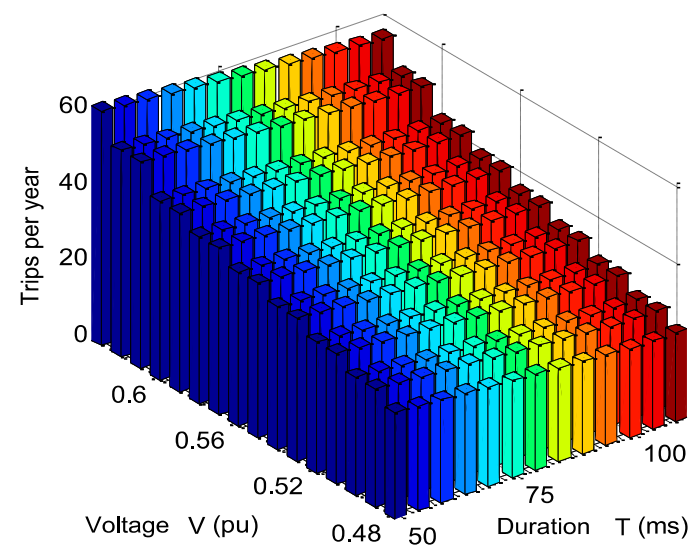

Figure 12. Number of expected equipment malfunction for PC at specified bus.

Figure 13 shows the probability of voltage-tolerance curves occurrence for PC with consideration of different types of sensitivity. These types of sensitivity are represented by various probability density functions described in Section 2.4.

If these probabilities are multiplied with the number of expected equipment trips, then we get expected number of equipment trips (in this case it is PC) for the corresponding voltage-tolerance curve (Figure 14). By summing up individual contributions of trips number per year, we get a value corresponding to the total estimated number of trips for a personal computer (connected to a given node), provided that the network configuration, sags frequency, etc. are not changed. In the same manner, we get the values for other types of sensitivity that use various probability density functions. 


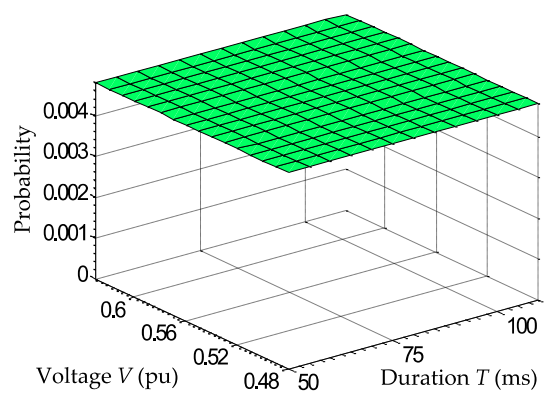

(a)

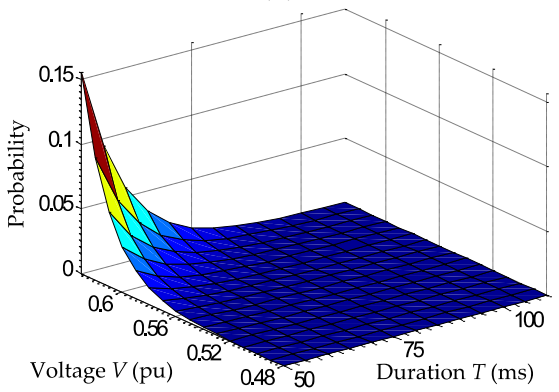

(c)

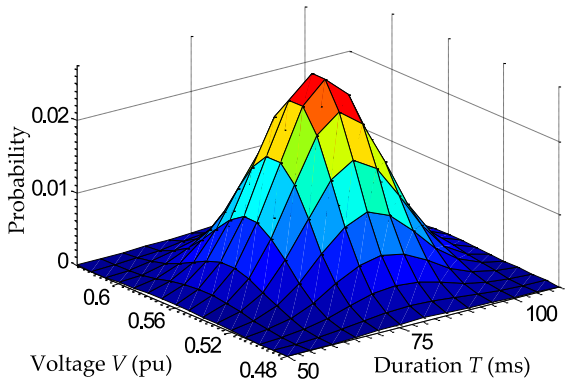

(b)

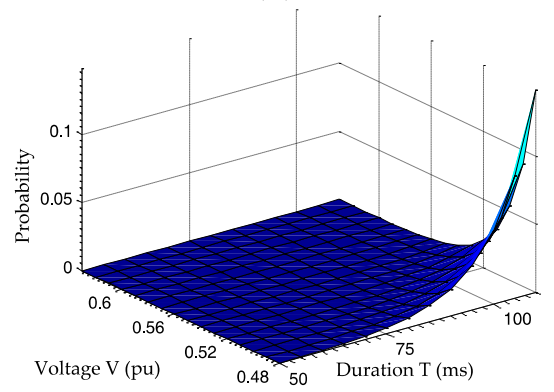

(d)

Figure 13. Probability of occurrence for voltage-tolerance characteristics for PC with assuming various density functions: (a) uniform; (b) normal; (c) exponential and (d) reverse exponential.

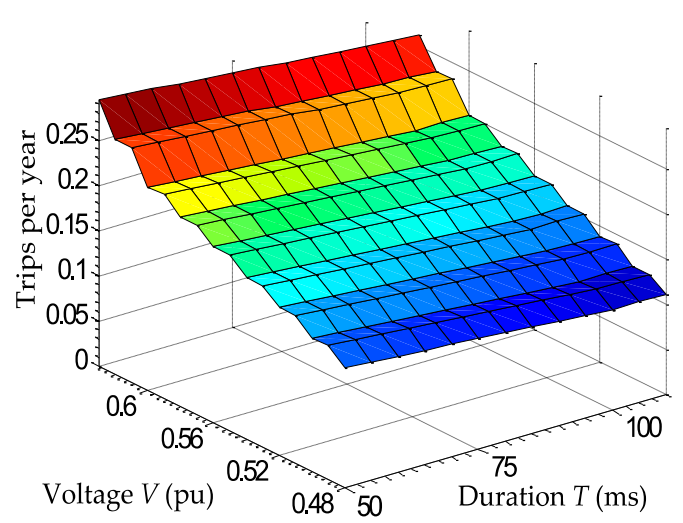

(a)

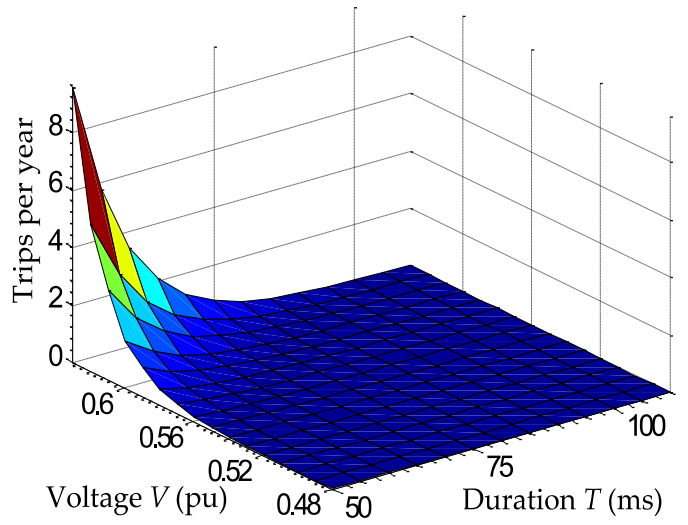

(c)

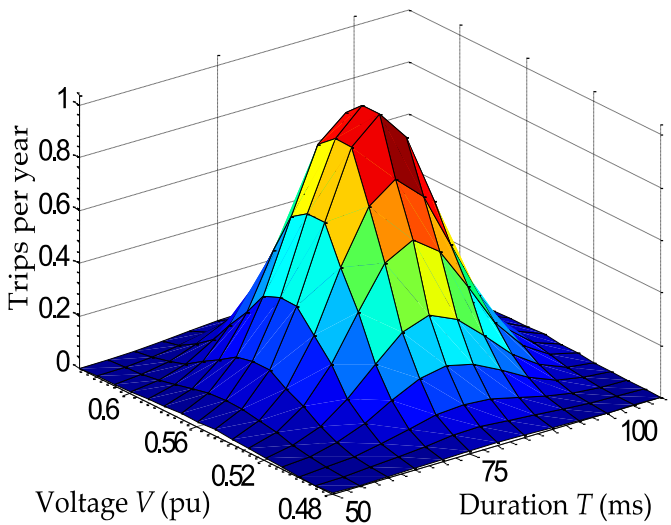

(b)

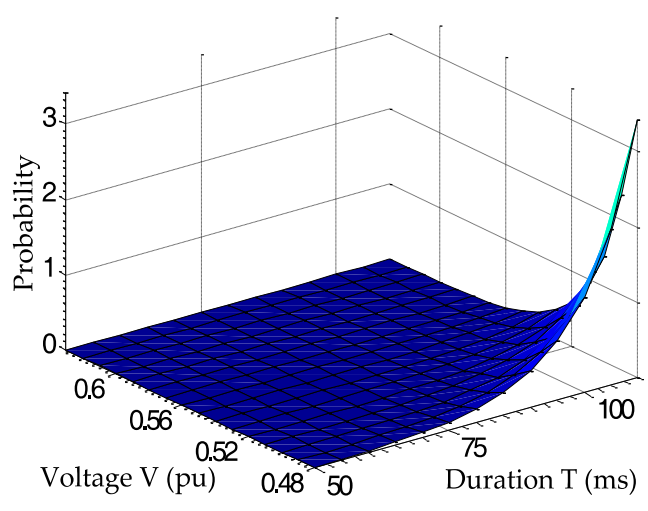

(d)

Figure 14. Number of expected trips a year of various voltage-tolerance characteristics for PC: (a) uniform; (b) normal; (c) exponential; and (d) reverse exponential. 


\subsubsection{Cumulative Probability Method}

This method has a similar calculation procedure but uses the distribution function of the probability distribution and $N(T, V)$ is the number of expected voltage sags (Figure 15). $N(T, V)$ in this case represents the number of expected voltage sags in the point for a specified time period. It is important to note that this method does not count only in the area of the equipment thresholds, but it is necessary to compute three additions to this area. Probability distribution function for two-dimensional variable is considered in thresholds area (sub-region III). However, two additions use probability distribution functions for one-dimensional variable. In sub-region $\mathrm{I}$, it is variable $T$ and in sub-region II it is variable $V$ (Figure 2a). The last addition is in the "red" area of trip and this has probability of voltage-tolerance curves occurrence equal to one in all its area.

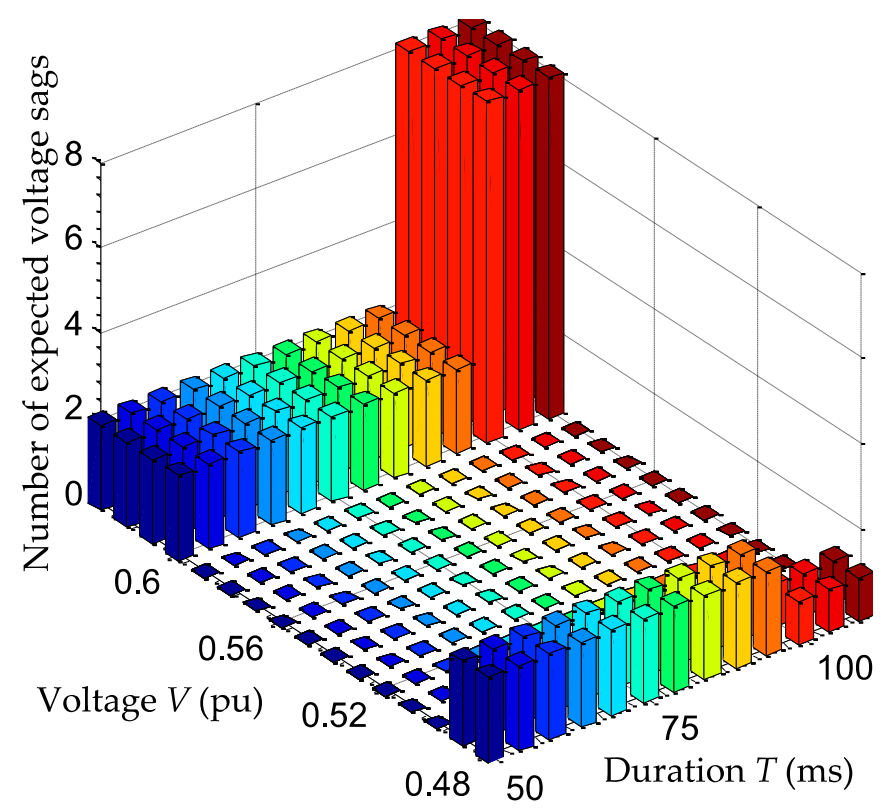

Figure 15. The expected number of voltage sags in a specified time period.

$N(T, V)$ number of expected voltage sags is determined from voltage sags frequency within the thresholds (Figure 16). Its distribution is based on the consideration that it is considered with only one voltage-tolerance curve at one time. It means that if voltage sags frequency is in the interval $0.4-0.5 \mathrm{pu}$ and $50-100 \mathrm{~ms}$ is 2 , all values $N(T, V)$ in this interval are equal to 2 .

Similar to general probability method, by multiplying the number of expected voltage sags (Figure 15) and probability of voltage-tolerance curves occurrence for equipment (Figure 16), it is possible to calculate estimated number of equipment trips (Figure 17).

Summarization of the number of PC trips for both methods for a given node and time period of one year is presented in Table 6. The table shows that the number of PC trips can vary from 23.77 to 54.894 depending on used sensitivity (probability function) and probability method. The biggest difference between the compared methods is 1.24 at using low sensitivity (reverse exponential).

For other devices, only expected numbers of trips are presented in the next sections, since the used methodology is the same as for the personal computers. 


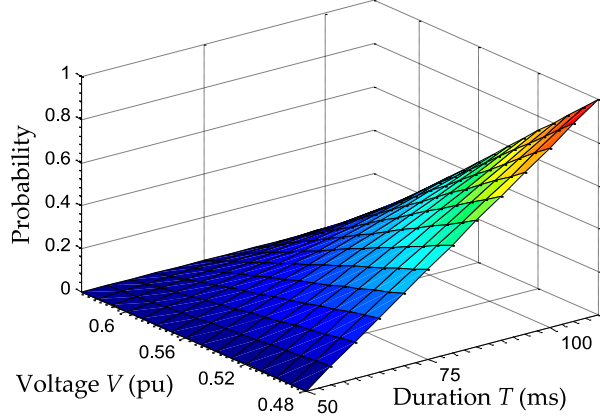

(a)

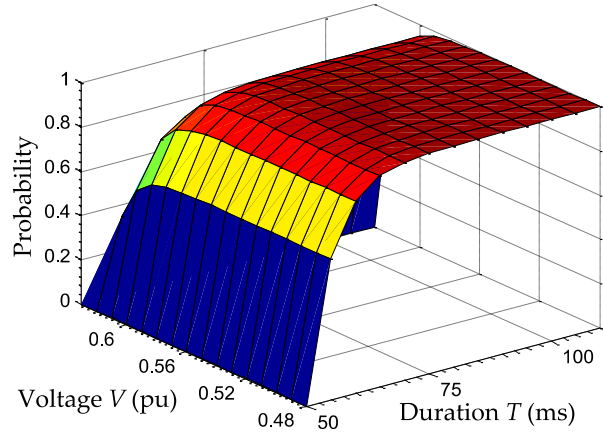

(c)

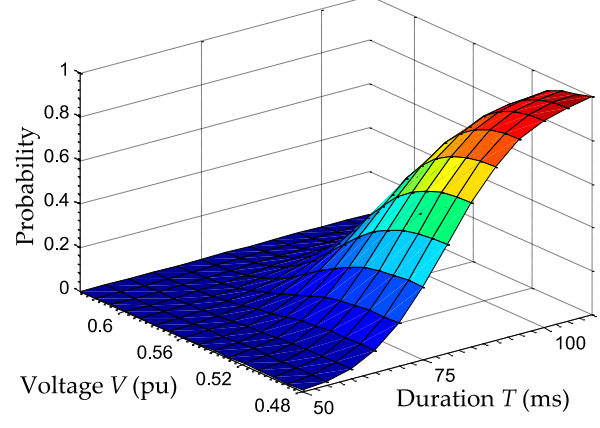

(b)

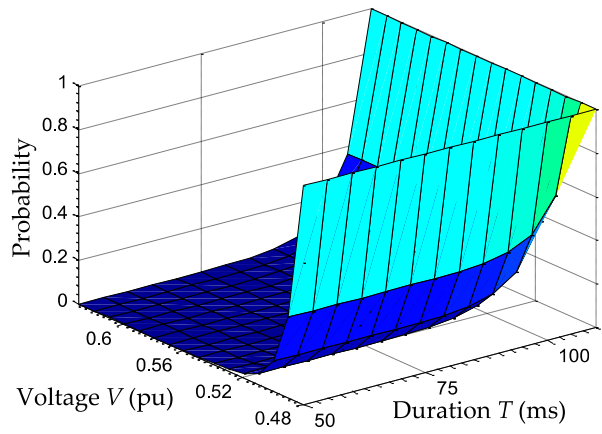

(d)

Figure 16. Probability of occurrence for voltage-tolerance characteristics for PC with assuming various density functions: (a) uniform; (b) normal; (c) exponential; and (d) reverse exponential.

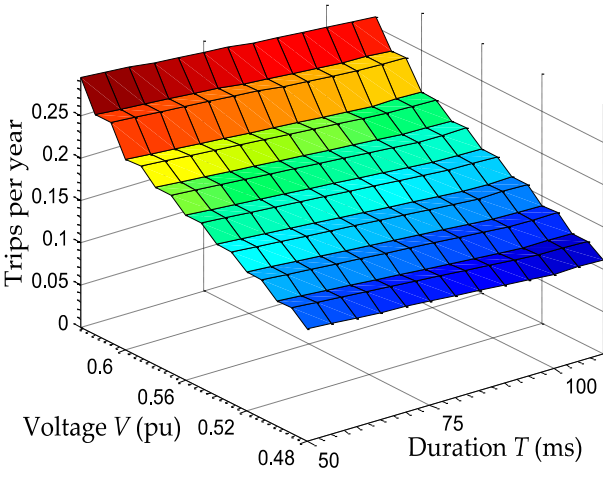

(a)

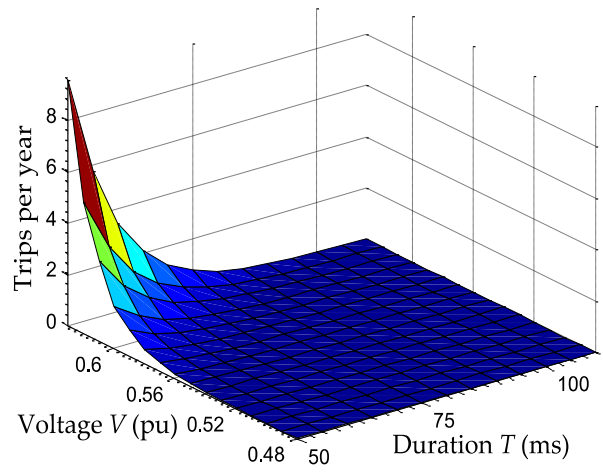

(c)

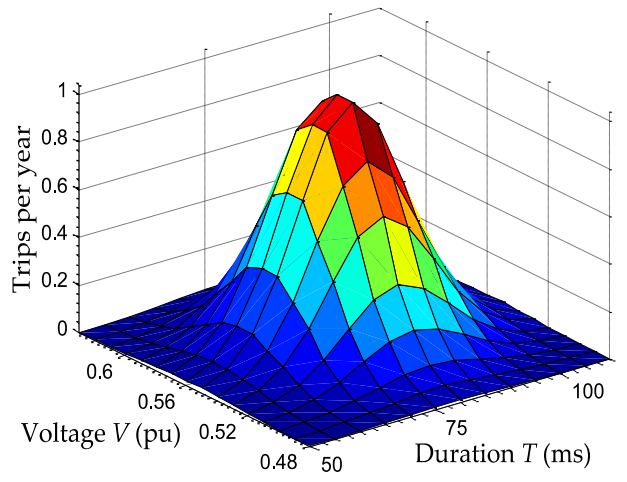

(b)

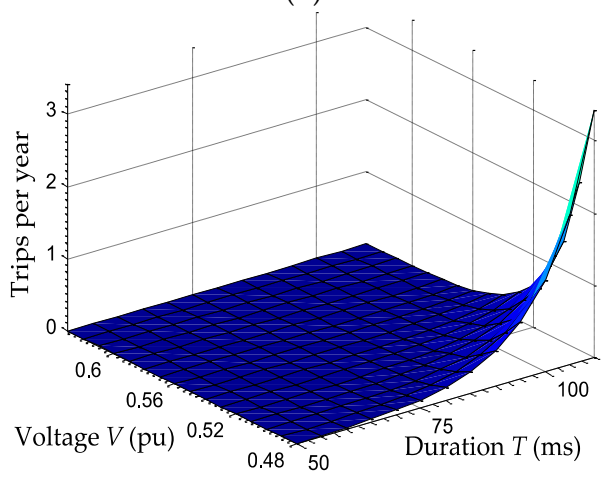

(d)

Figure 17. Number of expected trips per year of various voltage-tolerance characteristics for PC: (a) uniform; (b) normal; (c) exponential; and (d) reverse exponential. 
Table 6. Comparison of estimated total number of PC trips per year.

\begin{tabular}{cccc}
\hline Type of Distribution & General Approach & Cumulative Approach & Difference in Absolute Values \\
\hline Uniform & 38.64 & 38.2 & 0.44 \\
Normal & 37.554 & 37.517 & 0.037 \\
Exponential & 54.59 & 54.894 & 0.304 \\
Reverse exponential & 25.01 & 23.77 & 1.24 \\
\hline
\end{tabular}

\subsection{Number of Fluorescent Lamp Trips}

Fluorescent lamp trip occurs at critical value of voltage. After returning to original voltage value, fluorescent lamp burn again, if it is connected in standard manner. On the one hand, such flicker does not cause huge economic losses, but, on the other hand, it reduces comfort and safety at work, which should be more important than economic losses.

In this case, the calculation procedure is the same as for PC. Measured critical thresholds for fluorescent lamps are $V(0.22 \mathrm{pu}-0.62 \mathrm{pu})$ and $T(10 \mathrm{~ms}-55 \mathrm{~ms})$.

\subsubsection{General Probability Method}

Number of probabilistic trips of fluorescent lamps per year (Figure 18) were obtained by combining the probability of voltage-tolerance curves occurrence and the number of expected trips for fluorescent lamps within defined thresholds.

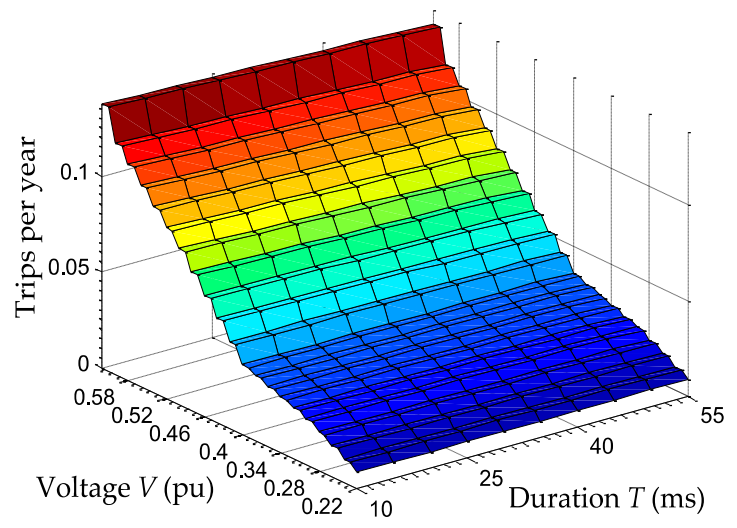

(a)

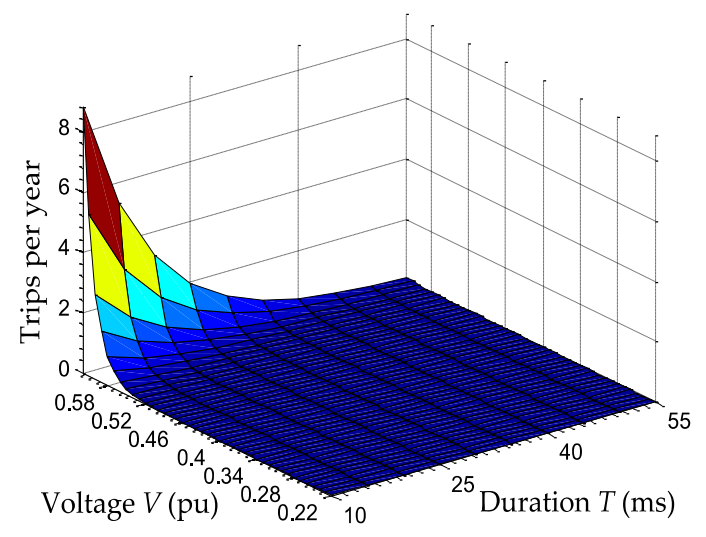

(c)

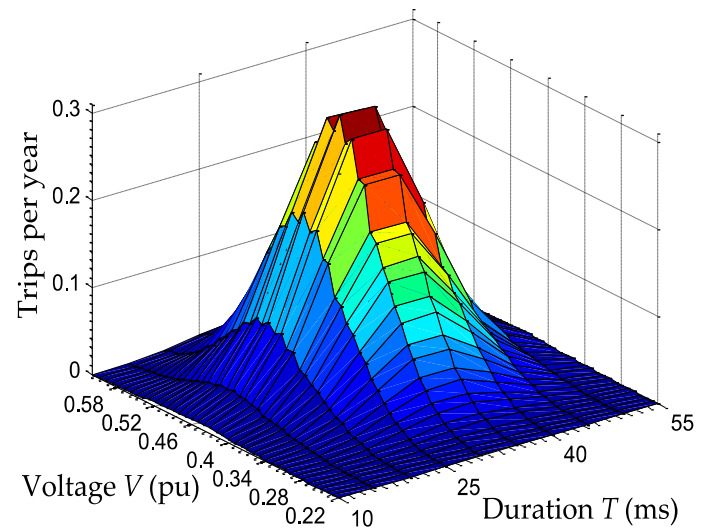

(b)

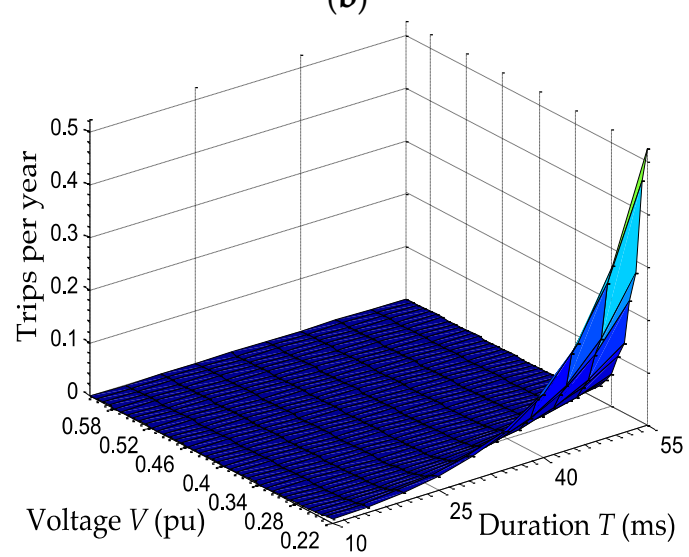

(d)

Figure 18. Number of expected trips per year of various voltage-tolerance characteristics for FL: (a) uniform; (b) normal; (c) exponential and (d) reverse exponential. 


\subsubsection{Cumulative Probability Method}

Likewise, the estimated number of FL trips (Figure 19) were obtained on the basis of theoretical relationships described in the cumulative probability method for PC, i.e., by combining the number of expected voltage sags and the probability of voltage-tolerance curves occurrence (using distribution functions of probability distribution).

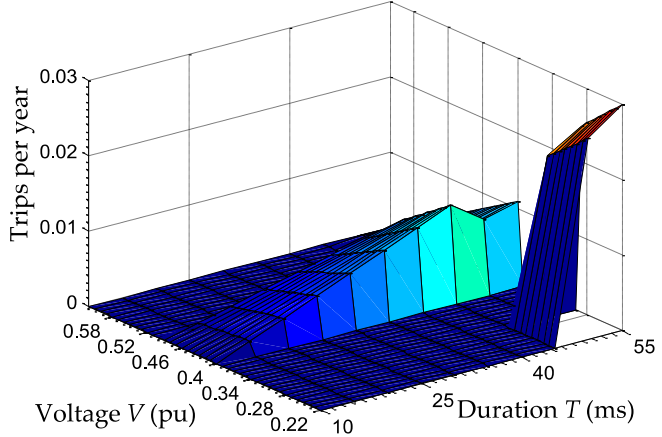

(a)

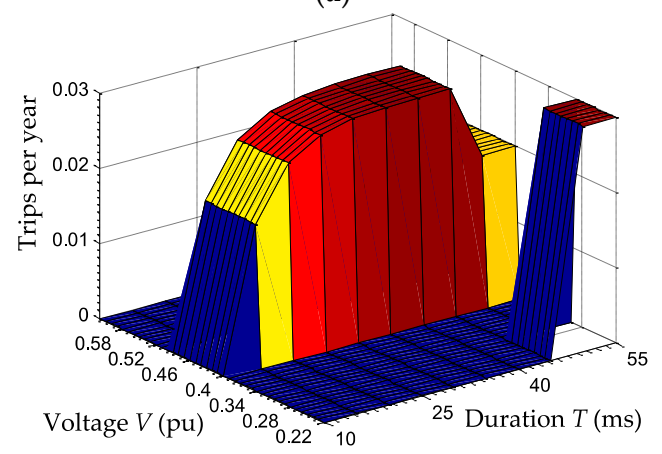

(c)

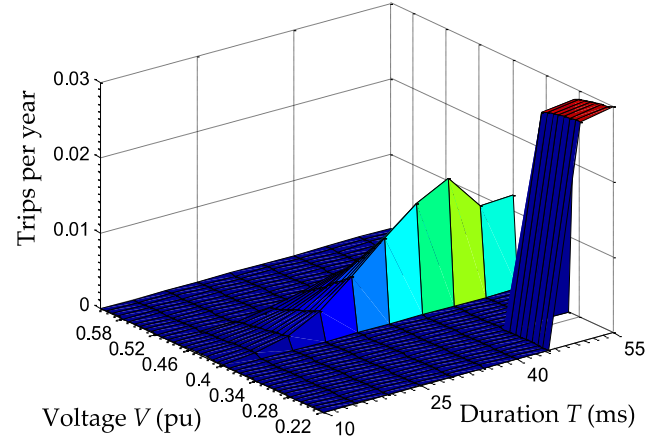

(b)

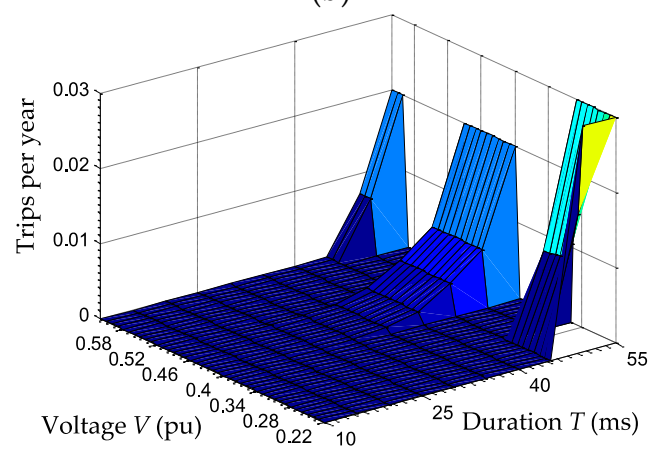

(d)

Figure 19. Number of expected trips per year of various voltage-tolerance characteristics for FL: (a) uniform; (b) normal; (c) exponential; and (d) reverse exponential.

Table 7 shows the number of FL trips per one year. The biggest difference in the results occurred at high sensitivity, approximately 1.232 trips per year.

Table 7. Comparison of estimated total number of FL trips per year.

\begin{tabular}{cccc}
\hline Type of Distribution & General Approach & Cumulative Approach & Difference in Absolute Values \\
\hline Uniform & 23.725 & 23.515 & 0.21 \\
Normal & 21.146 & 21.289 & 0.143 \\
Exponential & 52.95 & 54.182 & 1.232 \\
Reverse exponential & 4.843 & 4.26 & 0.583 \\
\hline
\end{tabular}

\subsection{Number of Adjustable Speed Drive Trips}

Representation of commonly used frequency converters for drive control in the industry is approximately $90 \%$. Voltage sags can cause change of the rotation speed or moment change (if we are not talking about total failure of equipment). Critical applications are equipped with a flywheel or other components that are more resistant to voltage sags. Currently, it is being solved with software "DC bus ripple elimination", which measures DC link voltage and adjusts the width of PWM signal for inverter, thereby effective value of voltage at inverter output changes to keep it constant. Considered critical thresholds for ASD drives are $V(0.69-0.9 \mathrm{pu})$ and $T(5-20 \mathrm{~ms})$. Figure 20 shows number of expected 
trips per year for general probability method (Figure 20a-d) and for cumulative probability method (Figure 20e-h) with different types of sensitivity.

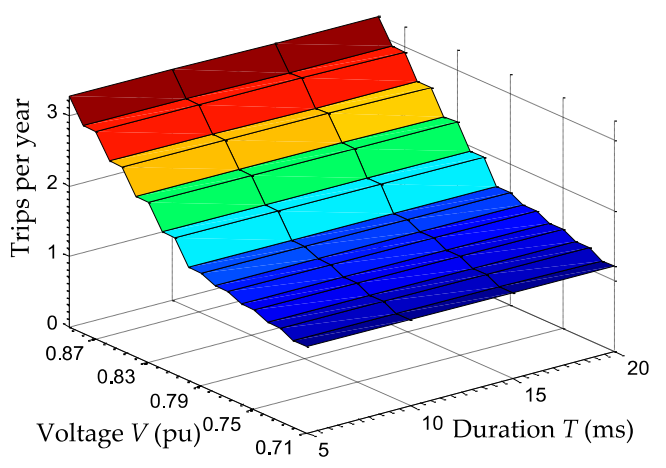

(a)

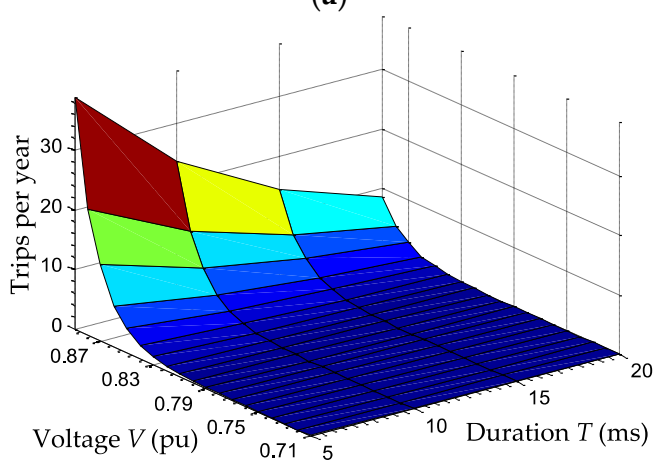

(c)

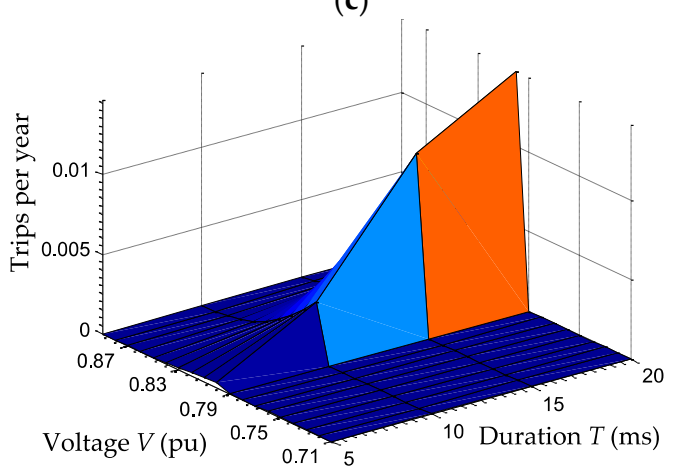

(e)

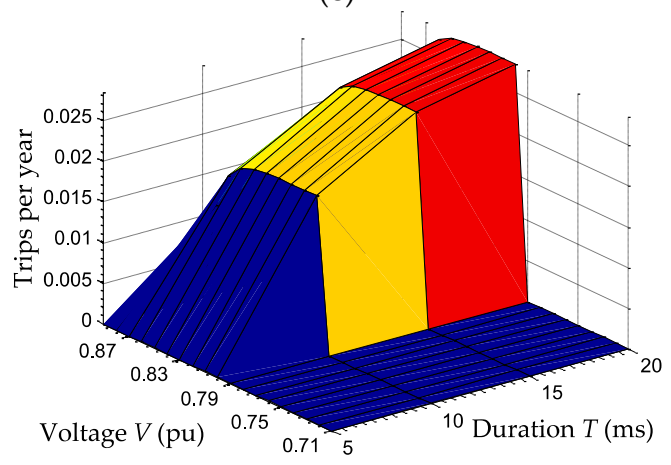

(g)

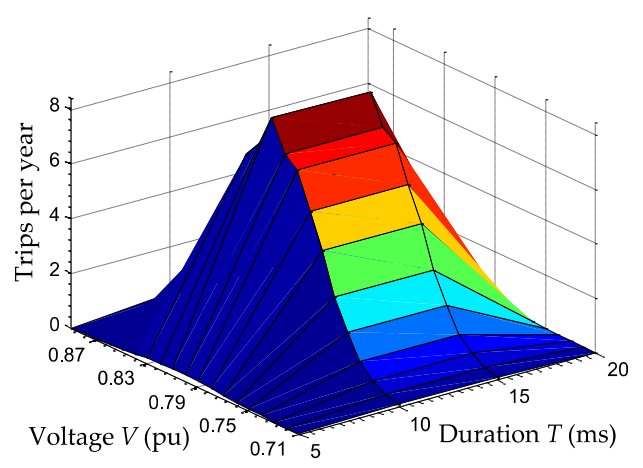

(b)

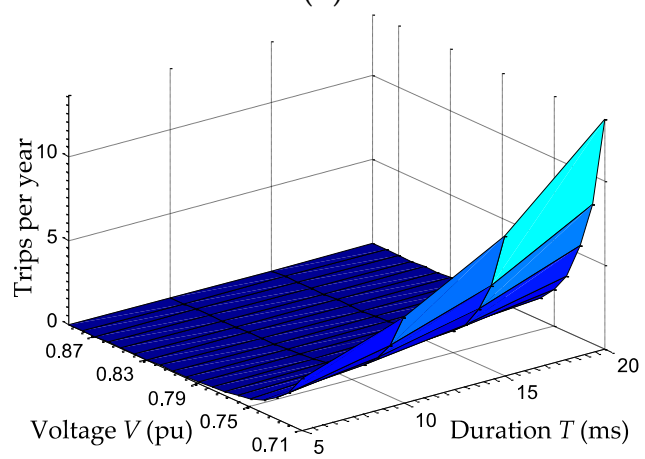

(d)

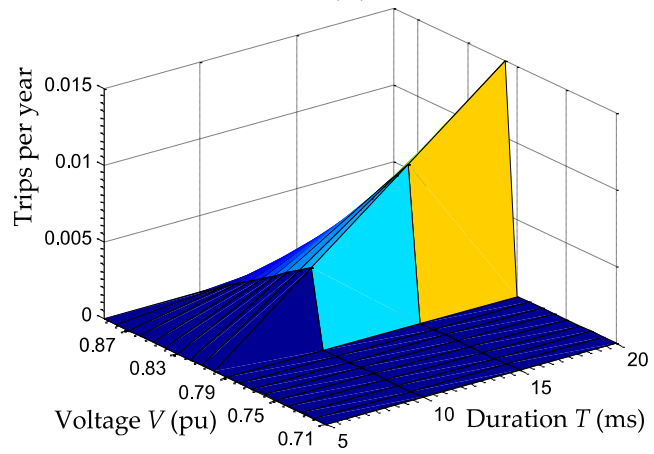

(f)

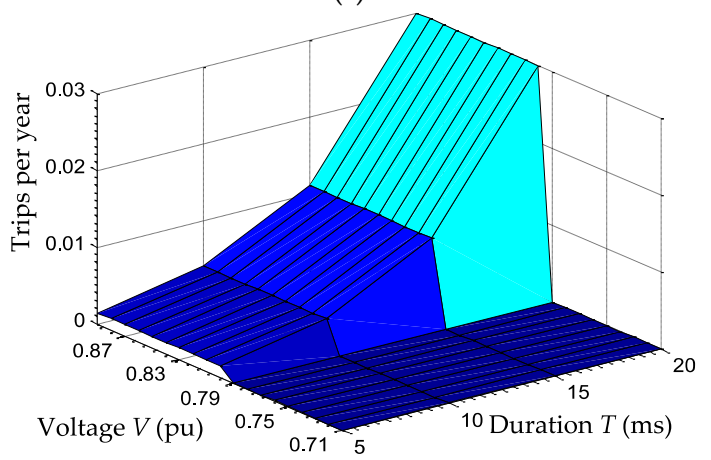

(h)

Figure 20. Number of expected trips per year of various voltage-tolerance characteristics for ASD: General probability method (a) uniform; (b) normal; (c) exponential; and (d) reverse exponential. Cumulative probability method (e) uniform; (f) normal; (g) exponential; and (h) reverse exponential. 
Measurements of voltage-tolerance curves and simulation results show that ASD devices are highly sensitive to voltage sags. Voltage-tolerance curves measurement was for three-phase symmetrical sag and the history of sags frequencies is constructed on the basis of all events, not only for three-phase symmetrical sags. More detailed history of voltage sags frequency would significantly improve this method. Therefore, it can be stated that the values in Table 8 are significantly lower than in the reality. Differences in the results of used methods are caused by narrow area of sag duration. This is caused by less precise probability distribution, especially for exponential functions.

Table 8. Comparison of estimated total number of ASD trips per year.

\begin{tabular}{cccc}
\hline Type of Distribution & General Approach & Cumulative Approach & Difference in Absolute Values \\
\hline Uniform & 147.158 & 145.675 & 1.483 \\
Normal & 135.347 & 136.925 & 1.578 \\
Exponential & 195.922 & 221.62 & 25.698 \\
Reverse exponential & 80.22 & 88.566 & 8.346 \\
\hline
\end{tabular}

\subsection{Number of Programmable Logic Controller Trips}

The use of PLC devices includes a wide spectrum of equipment, e.g., for machine control, technological processes, remote measurement and control, and diagnostics within specialized devices. Therefore, any failure of this equipment has a great economic impact, not only on the device itself but also on the processes controlled by the PLC. Considerable disadvantage of these devices is that error impulse or actuator can occur at PLC output during voltage sag, which often has worse economic impact than device restart. Critical thresholds for PLC devices are $V(0.69-0.9 \mathrm{pu})$ and $T(5-20 \mathrm{~ms})$. Figure 21 shows number of expected trips per year for general probability method with different types of sensitivity.

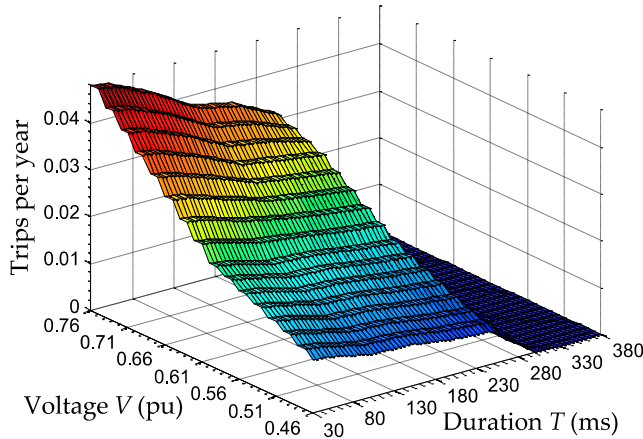

(a)

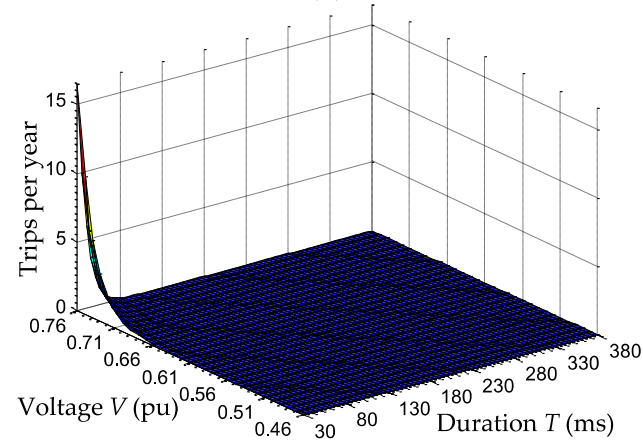

(c)

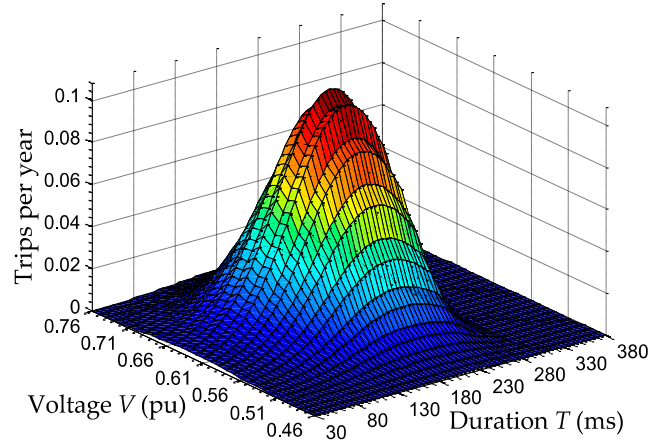

(b)

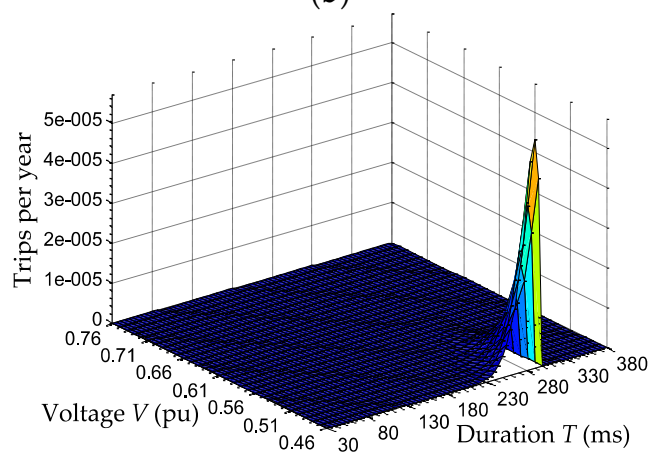

(d)

Figure 21. Number of expected trips per year of various voltage-tolerance characteristics for PLC: General probability method (a) uniform; (b) normal; (c) exponential; and (d) reverse exponential. 
With both probabilistic methods, in the area in the interval from 300 to $380 \mathrm{~ms}$, the value number of trips per year was equal to zero because $n$ voltage events were recorded in the interval from 300 to $350 \mathrm{~ms}$ (Figure 22) and duration interval $350 \mathrm{~ms}$ and above was not considered at all. Therefore, the calculation is made only for duration interval to $350 \mathrm{~ms}$ or to $300 \mathrm{~ms}$. Table 9 shows comparison of estimated total number of PLC trips per year.

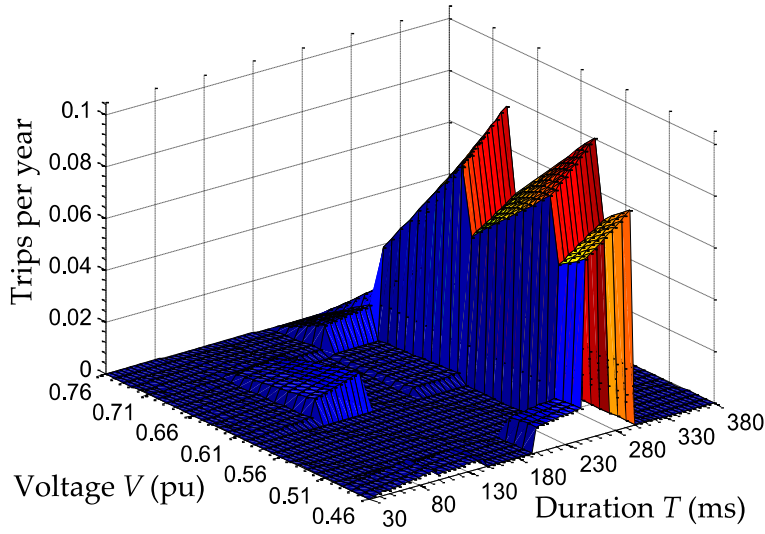

(a)

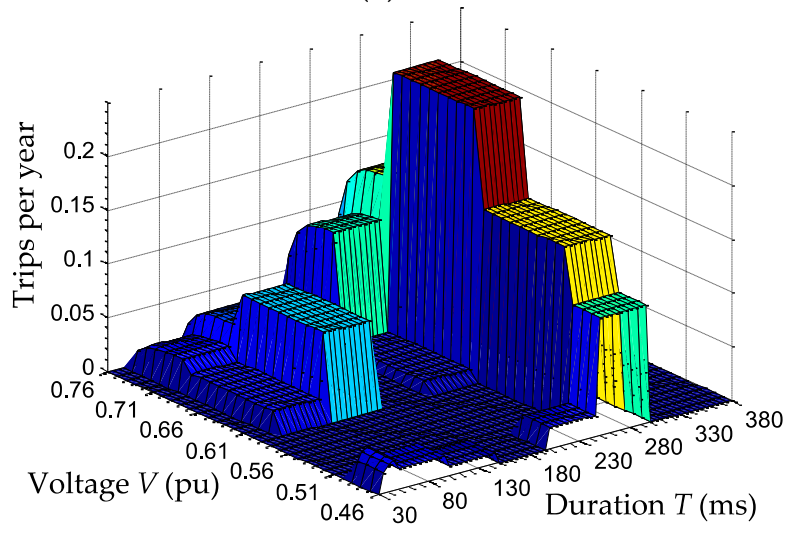

(c)

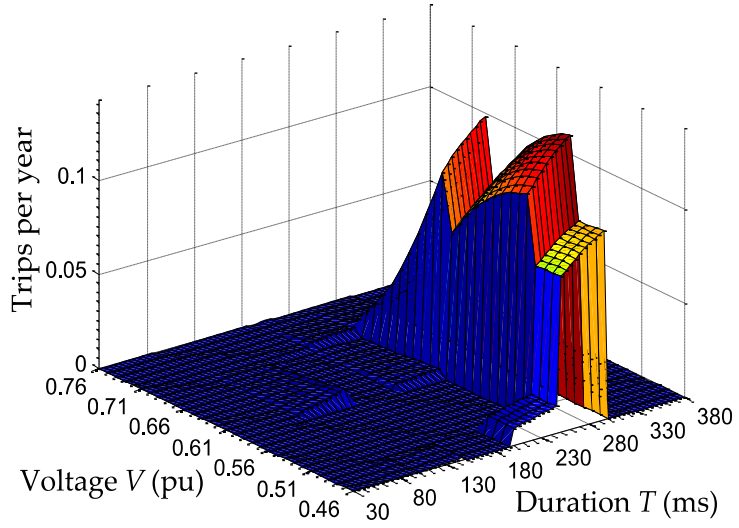

(b)

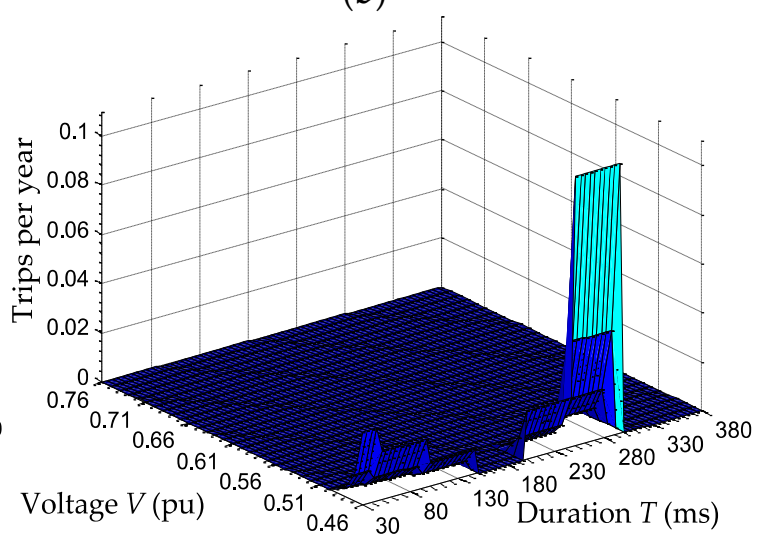

(d)

Figure 22. Number of expected trips per year of various voltage-tolerance characteristics for PLC: Cumulative probability method (a) uniform; (b) normal; (c) exponential; and (d) reverse exponential.

Table 9. Comparison of estimated total number of PLC trips per year.

\begin{tabular}{cccc}
\hline Type of Distribution & General Approach & Cumulative Approach & Difference in Absolute Values \\
\hline Uniform & 34.365 & 33.916 & 0.449 \\
Normal & 38.034 & 37.583 & 0.451 \\
Exponential & 101.969 & 103.214 & 1.245 \\
Reverse exponential & 0.001 & 2.717 & 2.716 \\
\hline
\end{tabular}

\subsection{Number of Contactor Trips}

\subsubsection{General Probability Method}

For determining the number of equipment trips, we considered two combinations of probability distributions. One of them is the combination of uniform and/or exponential distribution (Figure 23) and the other is the combination of uniform and/or normal distribution (Figure 24). The detailed descriptions of individual probability distributions used are described in the Section 2.1.3. 


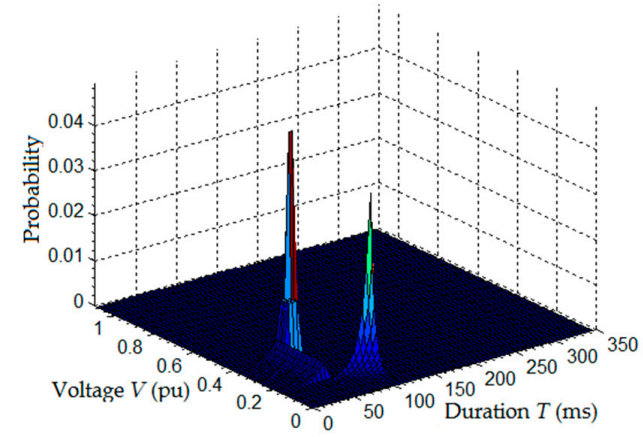

(a)

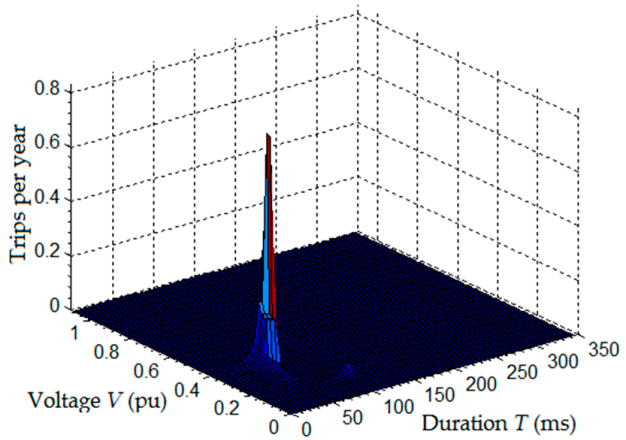

(b)

Figure 23. (a) Occurrence probability; and (b) number of expected equipment trips of various voltage-tolerance curves for contactors considering combination of probability distribution: uniform and/or exponential.

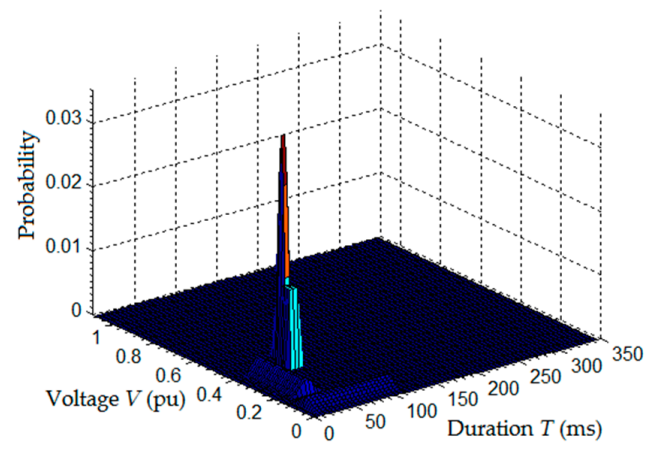

(a)

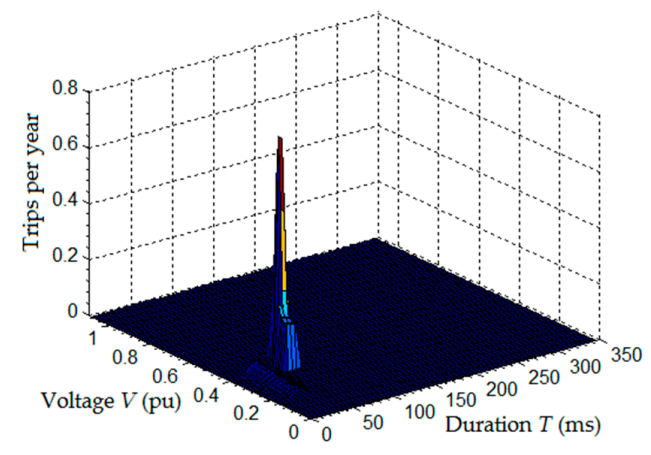

(b)

Figure 24. (a) Occurrence probability; and (b) number of expected equipment trips of various voltage-tolerance curves for contactors considering combination of probability distribution: uniform and/or normal.

\subsubsection{Cumulative Probability Method}

Number of expected contactor trips for combinations of probability distributions are shown in Figure 25. For cumulative method in sub-region 4 (Figure 8), not only one-dimensional variable along the $y$-axis, but also variable along the $x$-axis is considered. Only one threshold is defined for sub-region 4 and therefore it is necessary to count up to the maximum duration in sub-region 4 .

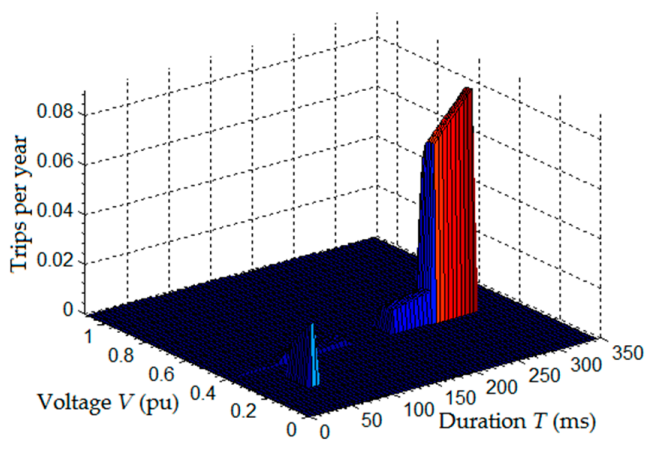

(a)

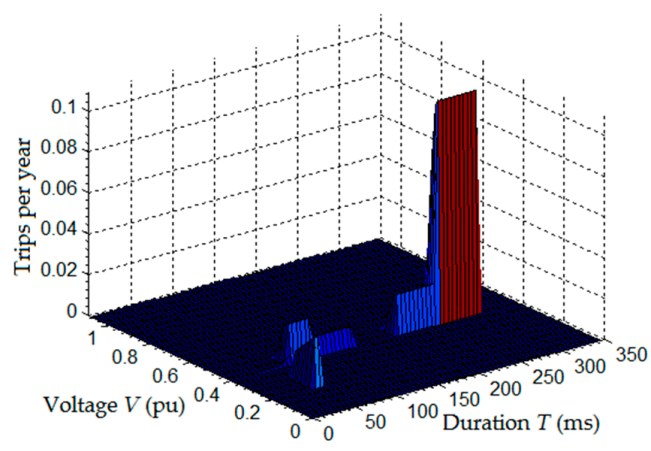

(b)

Figure 25. Number of expected contactor trips for combinations of probability distributions: (a) uniform and/or exponential; and (b) uniform and/or normal. 
The final comparison of the contactor trips number using two combinations of probability distributions is specified in Table 10.

Table 10. Comparison of estimated total number of contactor trips per year.

\begin{tabular}{cccc}
\hline Type of Distribution & General Approach & Cumulative Approach & Difference in Absolute Values \\
\hline $\begin{array}{c}\text { Uniform and/or } \\
\text { exponential } \\
\text { Uniform and/or } \\
\text { normal }\end{array}$ & 10.54 & 10.609 & 0.069 \\
\hline
\end{tabular}

\section{Conclusions}

The article deals with the determination of the number of equipment trips due to voltage sags. Based on comprehensive laboratory tests of sensitive equipment, voltage-tolerance characteristics of particular equipment were measured. The generalization of these calculations was made by joining voltage-tolerance characteristics of the same type of equipment to create area of uncertainty (e.g., for PC). For each type of distribution of probability at area of uncertainty, four various types of sensitivity (from low to high sensitivity) were considered. This was applied to all considered sensitive equipment. Type of sensitivity depends on operating conditions, characteristics of voltage sags and so on. For verification of correctness of the number of equipment trips at the specified bus calculation, two probability methods (cumulative and general method) were used. The final results of both methods were almost identical. It can be stated that these methods are suitable for estimation of the number of equipment trips due to voltage sags. This study can be expanded by more comprehensive measurement of sensitive equipment; for example, by changing the phase angle of voltage (point-on-wave) at the time of initiate voltage sag.

Practically, every severe voltage disturbance ultimately means financial loss. Almost $€ 400,000$ fine was paid as the compensation due to breach of voltage quality in Slovakia in 2016. Voltage sags are the most frequent disturbances from all voltage disturbances and therefore it is necessary to focus on it. Arising financial losses must be paid by someone. Following the reciprocal contract about quality of supply of power energy, financial losses have to be paid by distribution utility or customer. These probability methods can also be used for establishing the point of the high financial losses due to voltage sags, and focus on this point of distribution network in future investments. For more accurate results, older historical data (not only annual) of performance of voltage sag/swell at the specified bus are needed. This study is also usable for all busses at the network, if spread of the voltage sag at the given network is known.

This methodology also has utilization for electricity customer who is not secured with agreement on continuous operation with a specified power quality. With some probability, he knows to determine how high financial losses he would expect for a given period (e.g., for one year). Using this information, he would know whether it is more appropriate to invest in a compensation equipment (with a specified payback period) or backup system, or if he would be willing to tolerate the number of equipment trips. For example, if the number of equipment trips is sufficiently low, it is not worth investing in backup systems (considering return on investment).

Acknowledgments: This paper has been supported by the Slovak research and development agency (APVV) Nr: APVV-15-NEWPROJECT-8018: Efficiency increase of electricity transmission in TS SR.

Author Contributions: Marek Hoger created test stand for voltage sags generation that was used for measurement of voltage-tolerance characteristic of sensitive equipments. Roman Bodnar, Alena Otcenasova and Michal Repak created program in MATLAB for calculating data using the probabilistic methods. Roman Bodnar and Michal Regula analyzed the data and wrote the paper.

Conflicts of Interest: The authors declare no conflict of interest. 


\section{References}

1. Filho, J.M.C.; Abreu, J.P.G.; Arango, H.; Noronha, J.C.C. Analysis of Power System Performance under Voltage Sags; Electric Power Systems Research 55; Elsevier Science S.A.: Kidlington, UK, 2000; pp. 211-218.

2. Bodnar, R.; Otcenasova, A.; Regula, M.; Repak, M. Methodology for determination of the number of equipment malfunctions due to voltage quality. In Proceedings of the 16th International Conference on Environment and Electrical Engineering (EEEIC), Florence, Italy, 6-8 June 2016; pp. 1689-1694.

3. Gupta, C.P.; Milanovic, J.V. Probabilistic methods for counting equipment trips due to voltage sags. In Proceedings of the 9th International Conference on Probabilistic Methods Applied to Power Systems, Stockholm, Sweden, 11-15 June 2006; pp. 711-718.

4. Dugan, R.C.; McGranaghan, M.F.; Santoso, S.; Wayne Beaty, H. Electrical Power System Quality, 3rd ed.; McGraw-Hill Education: New York, NY, USA, 2012.

5. Milanovic, J.V.; Aung, M.T.; Gupta, C.P. The influence of fault distribution on stochastic prediction of voltage sags. IEEE Trans. Power Deliv. 2005, 20, 278-285. [CrossRef]

6. Dolara, A.; Leva, S. Power quality and harmonic analysis of end user devices. Energies 2012, 5, 5453-5466. [CrossRef]

7. Moreno-Garcia, I.M.; Moreno-Munoz, A.; Gil-de-Castro, A.; Bollen, M.; Gu, I.Y.H. Novel segmentation technique for measured three-phase voltage dips. Energies 2015, 8, 8319-8338. [CrossRef]

8. Sun, Y.; Li, P.; Li, S.; Zhang, L. Contribution determination for multiple unbalanced sources at the point of common coupling. Energies 2017, 10, 171. [CrossRef]

9. Whaite, S.; Grainger, B.; Kwasinski, A. Power quality in DC power distribution systems and microgrids. Energies 2015, 8, 4378-4399. [CrossRef]

10. Bollen, M.H.J. Understanding Power Quality Problems: Voltage Sags and Interruptions; IEEE Power Engineering Series; Wiley-IEEE Press: Hoboken, NJ, USA, 2000.

11. Cebrian, J.C.; Kagan, N.; Milanovic, J.V. Probabilistic estimation of distribution network performance with respect to voltage sags and interruptions considering network protection setting: Part I-The methodology. IEEE Trans. Power Deliv. 2005, PP. [CrossRef]

12. Chan, J.Y.; Milanovic, J.V. Severity indices for assessment of equipment sensitivity to voltage sags and short interruptions. In Proceedings of the IEEE Power Engineering Society General Meeting, Tampa, FL, USA, 24-28 June 2007.

13. Bodnar, R.; Otcenasova, A.; Altus, J.; Regula, M. Methodology for probabilistic estimation of equipment trips due to voltage sags. In Proceedings of the 8th International Scientific Symposium on Electrical Power Engineering, Stara Lesna, Slovakia, 16-18 September 2015.

14. Milanovic, J.V.; Gupta, C.P. Probabilistic assessment of financial losses due to interruptions and voltage sags-Part I: Methodology. IEEE Trans. Power Deliv. 2006, 21, 918-924. [CrossRef]

15. Park, C.H.; Hong, J.H.; Jang, G. Assessment of the system voltage sag performance based on the concept of area of severity. IET Gener. Transm. Distrib. 2010, 4, 683-693. [CrossRef]

16. Chan, J.Y.; Milanovic, J.V. Methodology for assessment of financial losses due to voltage sags and short interruptions. In Proceedings of the 9th International Conference on Electrical Power Quality and Utilisation, Barcelona, Spain, 9-11 October 2007.

17. Zhang, Y. Techno-Economic Assessment of Voltage Sag Performance on Mitigation. Ph.D. Thesis, The University of Manchester, Manchester, UK, 2008.

18. Avendane-Mora, M.; Milanovic, J.V.; Patel, B.; Zhang, Y. The influence of model parameters and uncertainties on assessment of netework Wide Costs of Voltage Sags. In Proceedings of the 10th International Conference on Electrical Power Quality and Utilisation, Lodz, Poland, 15-17 September 2009.

19. McGranagham, M.F.; Mueller, D.R.; Samotyj, M.J. Voltage sags in industrial systems. IEEE Trans. Ind. Appl. 1993, 29, 397-403. [CrossRef]

20. Pohjanheimo, P. A Probabilistic Method for Comprehensive Voltage Sag Management in Power Distribution Systems. Ph.D. Thesis, Department of Electronic Communication Engineering, Helsinki University of Technology, Helsinki, Finland, 2003.

21. Djokic, S.Z.; Desmet, J.; Vanalme, G. Sensitivity of personal computers to voltage sags and short interruptions. IEEE Trans. Power Deliv. 2005, 20, 375-383. [CrossRef] 
22. Djokic, S.Z.; Stockman, K.; Milanovic, J.V.; Desmet, J.M.; Belmans, R. Sensitivity of AC adjustable speed drives to voltage sags and short interruptions. IEEE Trans. Power Deliv. 2005, 20, 494-505. [CrossRef]

23. EPRI PQ Brief, Power Quality Target, No. 46. Performance of a Hold-In Device for Relays, Contactors and Motor-Starters. 2007. Available online: http://www.epri.com/abstracts/Pages/ProductAbstract.aspx? ProductId=000000000001017056 (accessed on 10 February 2017).

24. Voltage Dip Immunity of Equipment and Installations. Available online: http:/ /www.uie.org/voltage-dipimmunity-equipment-and-installations (accessed on 5 February 2017).

25. Djokic, S.Z. Generalized Methodology for the Assessment of Voltage Sag Performance Indices and Equipment Sensitivity. Ph.D. Thesis, UMIST, Manchester, UK, 2004.

26. Bok, J.; Drapela, J.; Slezingr, J. Function criteria definition for testing of light sources immunity to voltage dips and short interruptions. In Proceedings of the 12th International Scientific Conference on Electric Power Engineering (EPE), Kouty nad Desnou, Czech Republic, 17-19 May 2011; pp. 635-639.

27. Hardi, S.; Hafizi, M.; Isa, M.; Ismail, R. Equipment performance due to voltage sags-Test results for contactor and induction motor. GSTF J. Eng. Technol. (JET) 2013, 2, 46-51. [CrossRef]

28. Küfeoğlu, S.; Lehtonen, M. Macroeconomic assessment of voltage sags. Sustainability 2016, 8, 1304. [CrossRef]

29. Bodnar, R.; Otcenasova, A.; Regula, M.; Repak, M. Methodology for quantification of equipment trips due to voltage sags. In Proceedings of the 11th International Conference ELEKTRO, 16-18 May 2016; pp. 264-268.

30. Weldemariam, L.; Cuk, V.; Cobben, J. Cost estimation of voltage dips in small industries based on equipment sensitivity analysis. Smart Grid Renew. Energy 2016, 7, 271-292. [CrossRef]

31. Yang, D.; Wang, Y.; Xiao, X.; Xu, W. The uncertainty assessment of sensitive equipment voltage sags ride-through ability based on maximum hybrid entropy. In Proceedings of the Energy Conversion Congress and Exposition (ECCE), Raleigh Convention Centre, Raleigh, NC, USA, 15-20 September 2012.

32. Electric Power Research Institute (EPRI). Power Quality Testing Network: Brief; Ride-Through Performance of Programmable Logic Controllers, Brief No. 39; Electric Power Research Institute: Palo Alto, CA, USA, 2007.

33. Gupta, C.P.; Milanovic, J.V. Probabilistic assessment of equipment trips due to voltage sags. IEEE Trans. Power Deliv. 2006, 21, 711-718. [CrossRef]

34. Hasan, M.S.; Muttaqi, K.M.; Bouzerdoum, A. Characterization of voltage sag based on Point-on-Wave. In Proceedings of the 9th International Conference on Electrical and Computer Engineering (ICECE), Dhaka, Bangladesh, 20-22 December 2016; pp. 264-268.

35. Djokic, S.Z.; Milanovic, J.V.; Kirschen, D.S. Sensitivity of AC coil contactors to voltage sags, short interuptions and under-voltage transients. IEEE Trans. Power Deliv. 2004, 19, 1299-1307. [CrossRef]

36. Brown, R.G.; Hwang, P.Y.C. Introduction to Random Signals and Applied Kalman Filtering; John Wiley and Sons: New York, NY, USA, 1997.

(C) 2017 by the authors. Licensee MDPI, Basel, Switzerland. This article is an open access article distributed under the terms and conditions of the Creative Commons Attribution (CC BY) license (http:/ / creativecommons.org/licenses/by/4.0/). 